\title{
5-Iodo-1-Arylpyrazoles as Potential Benchmarks for Investigating the Tuning of the Halogen Bonding
}

\author{
Denisa Dumitrescu ${ }^{1}$, Sergiu Shova ${ }^{2}{ }^{(1)}$, Isabela C. Man $\left.{ }^{3}{ }^{(}\right)$, Mino R. Caira ${ }^{4}$, \\ Marcel Mirel Popa ${ }^{3, *(\mathbb{D})}$ and Florea Dumitrascu ${ }^{3, *}$ \\ 1 Faculty of Pharmacy, Ovidius University Constanta, Campus Corp C, Str. Cpt. Av. Al. Serbanescu, \\ 900470 Constanta, Romania; denisa.dumitrescu2014@gmail.com \\ 2 "Petru Poni" Institute for Macromolecular Chemistry, Department of Inorganic Polymers, \\ Romanian Academy, Aleea Grigore Ghica Voda, 41A, 700487 Iasi, Romania; shova@icmpp.ro \\ 3 “C.D. Nenitzescu" Center for Organic Chemistry, Romanian Academy, Spl. Independetei 202B, \\ 060023 Bucharest, Romania; isabelac.man@gmail.com \\ 4 Department of Chemistry, University of Cape Town, Rondebosch 7701, South Africa; Mino.Caira@uct.ac.za \\ * Correspondence: mirelupb@gmail.com (M.M.P.); fdumitra@yahoo.com (F.D.)
}

Received: 24 November 2020; Accepted: 14 December 2020; Published: 17 December 2020

\begin{abstract}
Iodo-1-arylpyrazoles are interesting templates for investigating the halogen bond propensity in small molecules other than the already well-known halogenated molecules such as tetrafluorodiiodobenzene. Herein, we present six compounds with different substitution on the aryl ring attached at position 1 of the pyrazoles and investigate them in the solid state in order to elucidate the halogen bonding significance to the crystallographic landscape of such molecules. The substituents on the aryl ring are generally combinations of halogen atoms $(\mathrm{Br}, \mathrm{Cl})$ and various alkyl groups. Observed halogen bonding types spanned by these six 5-iodopyrazoles included a wide variety, namely, $\mathrm{C}-\mathrm{I} \cdots \mathrm{O}, \mathrm{C}-\mathrm{I} \cdots \pi, \mathrm{C}-\mathrm{I} \cdots \mathrm{Br}, \mathrm{C}-\mathrm{I} \cdots \mathrm{N}$ and $\mathrm{C}-\mathrm{Br} \cdots \mathrm{O}$ interactions. By single crystal $\mathrm{X}$-ray diffraction analysis combined with the descriptive Hirshfeld analysis, we discuss the role and influence of the halogen bonds among the intermolecular interactions.
\end{abstract}

Keywords: halogen bond; $\sigma$-hole; 5-iodo-pyrazole; X-ray diffraction; Hirshfeld analysis

\section{Introduction}

The propensity and utility of the halogen bond [1,2] is already well established in materials chemistry [3-6], many applications from crystal engineering [7-12] to halogen-bonded catalyzed reactions [12-18] and even more to smart materials [3-6] or medicinal chemistry [19-27] being currently reported. Both in solution [28-32] and in the solid state, halogen bonding seems to be developing into a promising field.

The central concept of the halogen interactions is the so-called sigma-hole [33-41], which is briefly a formal positive potential on the extremity of the halogen atom that is more likely to interact with nucleophilic entities. Halogen bonding was first investigated in the case of halogen-halogen interactions which were defined as type I and type II [1,2,42], and more recently an unconventional type III halogen or di- $\sigma$-hole [43] has been reported (Figure 1b). However, the concept was extended to different halogen-B interactions, where B could be any Lewis base or other electronegative molecular entity. More particularly, halogen-oxygen, halogen-nitrogen or halogen- $\pi$ (Figure $1 c$ ) interactions were reported both in liquid and solid state. 


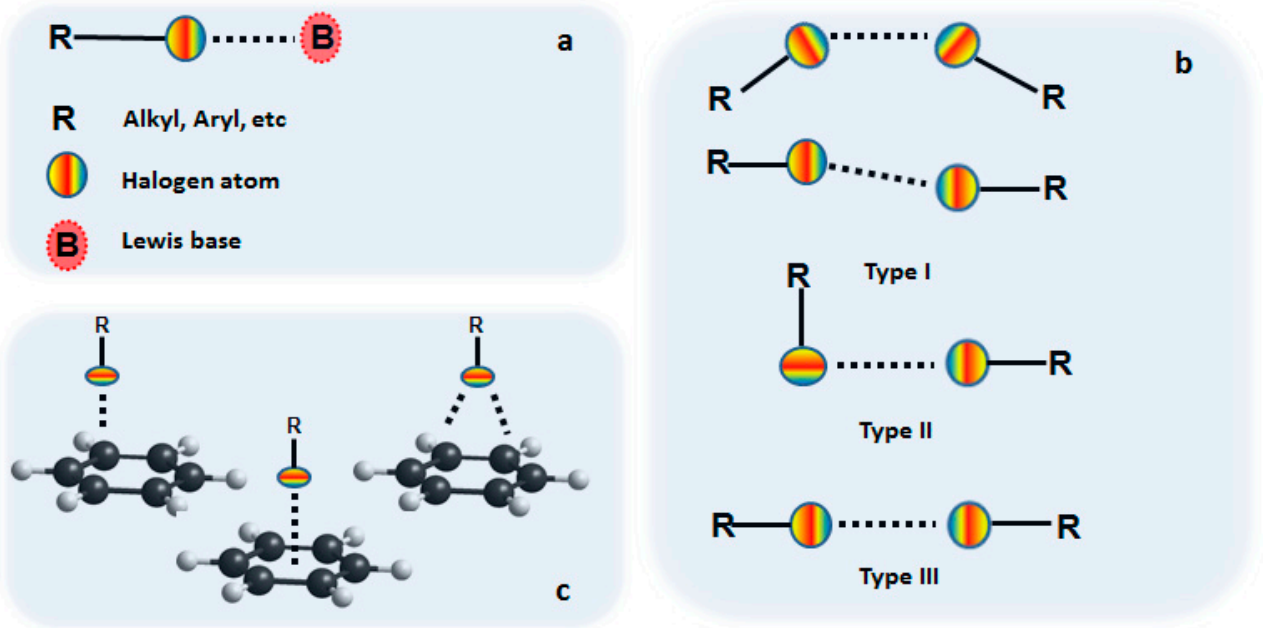

Figure 1. General description of a halogen bond and the types of halogen interactions (blue color depicts the $\sigma$-hole): (a) general description of the halogen bond; (b) halogen-halogen interactions; (c) halogen- $\pi$ interactions (over-the-atom, over-the-bond and over-the-ring).

We recently discovered that halogenated sydnones [44,45] and pyrazoles [46] are molecules with high potential for investigating the propensity of halogen bonding and its contribution among the other intermolecular interactions. We reported three types of halogen bonding in our investigations, all involving the iodine atom: $\mathrm{I} \cdots \mathrm{N}, \mathrm{I} \cdots \mathrm{O}$ and $\mathrm{I} \cdots \pi[46]$. During our investigation, we also showed, with examples from the Cambridge Structural Database (CSD), that halogen interactions are important intermolecular forces which can either stabilize or even direct the crystalline network.

We proposed to expand our investigational endeavor to a library of iodinated pyrazoles by introducing also other halogen atoms such as bromine or different substituents on the phenyl ring of the 1-arylpyrazoles in order to study the halogen bonding and its relation to other intermolecular interactions.

Therefore, suitable crystals for six new 5-iodinated-1-arylpyrazoles were obtained by slow evaporation from different solvents and investigated by single crystal $\mathrm{X}$-ray diffraction analysis and using descriptive tools such as Hirshfeld analysis and quantum computations.

\section{Materials and Methods}

\subsection{Synthesis and Crystal Growth}

The 5-iodopyrazoles under investigation (Table 1) were synthesized by 1,3-dipolar cycloaddition of the corresponding 4-iodosydnones with dimethyl acetylenedicarboxylate via a previously described procedure [45,47-50].

Suitable crystals were grown by slow evaporation from acetonitrile (compounds 1, 2, 4 and 5) or a mixture of ethanol and dichloromethane 1:2 $v / v$ (compounds 3 and 6).

\subsection{X-ray Diffraction Analysis}

X-ray diffraction measurements were carried out with a Rigaku Oxford-Diffraction XCALIBUR E CCD diffractometer equipped with graphite-monochromated MoK $\alpha$ radiation. The unit cell determination and data integration were carried out using the CrysAlis package of Oxford Diffraction [51]. The structures were solved by Intrinsic Phasing using Olex2 [52] software with the SHELXT [53] structure solution program and refined by full-matrix least-squares on $\mathrm{F}^{2}$ with SHELXL-2015 [54] using an anisotropic model for non-hydrogen atoms. All $\mathrm{H}$ atoms attached to carbon were introduced in idealized positions $\left(\mathrm{d}_{\mathrm{CH}}=0.96 \AA\right)$ using the riding model. The molecular plots were obtained using the Olex 2 program. Table 1 provides a summary of the 
crystallographic data together with refinement details for compounds. The geometric parameters are summarized in Table S1. The values of the geometrical parameters are in the expected ranges for compounds in this class. The supplementary crystallographic data can be obtained free of charge via www.ccdc.cam.ac.uk/conts/retrieving.html (or from the Cambridge Crystallographic Data Centre, 12 Union Road, Cambridge CB2 1EZ, UK; Fax: +44-1223-336-033; or deposit@ccdc.ca.ac.uk).

\subsection{Hirshfeld Analysis}

Hirshfeld analysis was performed using CystalExplorer [55,56]. By definition, the Hirshfeld surface maps intermolecular contacts, and essentially it is computed at the sum of $d_{e}$ and $d_{i}$, the distances from the external atoms to the surface and internal atoms to the Hirshfeld surface, respectively [56]. Sums of distances shorter than the sum of the vdW radii of two neighboring atoms are marked with red spots, distances close to the vdW radii in white and distances larger than vdW in blue color. Moreover, the fingerprint plots [56] show a qualitative description of all the relevant contacts in the crystal packing, by plotting in a $2 \mathrm{D}$ graph $\mathrm{d}_{\mathrm{i}}$ and $\mathrm{d}_{\mathrm{e}}$, which are the distances from the contact atoms to the Hirshfeld surface, creating a "heatmap" of non-covalent interactions.

\section{Results and Discussion}

In a recent study [46], we investigated the propensity for 5-iodopyrazoles (Figure 2) to form halogen bonds. We observed the tendencies of 5-iodopyrazoles and 4-iodosydnones [44-46] to form halogen bond interactions with several Lewis bases by ${ }^{13} \mathrm{C}-\mathrm{NMR}$ spectroscopy in solution and this subsequently prompted us to focus on solid-state interactions in such compounds. Interestingly, the iodine atom in the proposed 5-iodo-1-arylpyrazoles was found to be involved in C-I $\cdots \mathrm{N}, \mathrm{C}-\mathrm{I} \cdots \mathrm{O}$ and $\mathrm{C}-\mathrm{I} \cdots \pi$ type interactions, and this was consistent with interactions observed in other similar structures from the CSD [46,57].
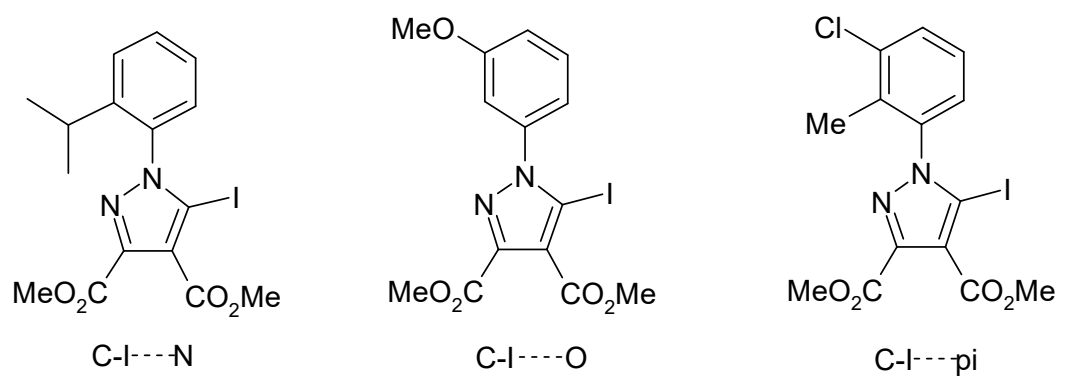

Figure 2. Previously investigated structures and types of halogen interactions observed.

With the aim of extending our studies, we investigated a library of six new iodopyrazole structures by single crystal X-ray diffraction analysis. The structural variation of the six compounds was ensured by the different substituents on the aryl ring, which were chosen bearing in mind both steric factors that might be induced by bulky groups in the ortho position of the aryl residue, and the introduction of other halogen atoms such as $\mathrm{Br}$ or $\mathrm{Cl}$, which had also proven to be involved in halogen non-covalent interactions.

Crystals of the pyrazoles 1-6 were subjected to single crystal X-ray diffraction analysis and the measured parameters are presented in Table 1. 
Table 1. The structures of the iodinated pyrazoles 1-6 and X-ray diffraction crystal parameters for each compound.

\begin{tabular}{|c|c|c|c|}
\hline Compound & & $\mathrm{Me}$ & $\mathrm{Br}$ \\
\hline \multirow[t]{2}{*}{ X-ray Parameters } & & $\mathrm{CO}_{2} \mathrm{Me}$ & $\mathrm{MeO}_{2} \mathrm{C}$ \\
\hline & 1 & 2 & 3 \\
\hline Empirical formula & $\mathrm{C}_{14} \mathrm{H}_{13} \mathrm{IN}_{2} \mathrm{O}_{4}$ & $\mathrm{C}_{15} \mathrm{H}_{15} \mathrm{IN}_{2} \mathrm{O}_{4}$ & $\mathrm{C}_{14} \mathrm{H}_{12} \mathrm{BrIN}_{2} \mathrm{O}_{4}$ \\
\hline$F w$ & 400.16 & 414.19 & 479.07 \\
\hline$T[\mathrm{~K}]$ & $293(2)$ & $293(2)$ & $281(2)$ \\
\hline space group & $P 2 / c$ & $P 22_{1} / c$ & $\mathrm{Pbca}$ \\
\hline$a[\AA]$ & $11.9709(13)$ & $15.0655(10)$ & $10.3287(8)$ \\
\hline$b[\AA]$ & $16.994(2)$ & $11.2635(11)$ & $15.3048(12)$ \\
\hline$c[\AA]$ & $7.8913(11)$ & $9.7028(8)$ & $21.492(2)$ \\
\hline$\alpha\left[^{\circ}\right]$ & 90 & 90 & 90 \\
\hline$\beta\left[^{\circ}\right]$ & $105.461(14)$ & $92.930(7)$ & 90 \\
\hline$\gamma\left[{ }^{\circ}\right]$ & 90 & 90 & 90 \\
\hline$V\left[\AA^{3}\right]$ & $1547.3(4)$ & $1644.3(2)$ & $3397.4(5)$ \\
\hline Z & 4 & 4 & 8 \\
\hline$\rho$ calcd $\left[\mathrm{g} \mathrm{cm}^{-3}\right]$ & 1.718 & 1.673 & 1.873 \\
\hline$\mu\left[\mathrm{mm}^{-1}\right]$ & 2.086 & 1.966 & 4.255 \\
\hline Crystal size $[\mathrm{mm}]$ & $0.30 \times 0.25 \times 0.15$ & $0.30 \times 0.05 \times 0.03$ & $0.35 \times 0.25 \times 0.25$ \\
\hline $2 \Theta$ range $\left[{ }^{\circ}\right]$ & 4.268 to 50.054 & 4.518 to 50.052 & 3.79 to 50.048 \\
\hline Reflections collected & 8831 & 7765 & 8816 \\
\hline Independent reflections & $2727\left[R_{\text {int }}=0.0260\right]$ & $2904\left[R_{\text {int }}=0.0468\right]$ & $2996\left[R_{\text {int }}=0.0615\right]$ \\
\hline Data/restraints/parameters & $2727 / 0 / 193$ & $2904 / 0 / 199$ & $2996 / 0 / 202$ \\
\hline $\mathrm{GOF}^{\mathrm{c}}$ & 1.095 & 1.083 & 1.028 \\
\hline$R_{1}^{a}$ & 0.0317 & 0.0602 & 0.0534 \\
\hline$w \mathrm{R}_{2}^{\mathrm{b}}$ & 0.0592 & 0.0856 & 0.1256 \\
\hline $\begin{array}{l}\text { Largest diff. peak/hole } \\
\left.\text { [e } \AA^{-3}\right]\end{array}$ & $0.34 /-0.27$ & $0.54 /-0.57$ & $0.79 /-1.2$ \\
\hline CCDC number & 2039133 & 2039134 & 2039135 \\
\hline \multirow[t]{2}{*}{ X-ray Parameters } & $\mathrm{MeO}_{2} \mathrm{C}^{\prime}$ & $\mathrm{MeO}_{2} \mathrm{C}$ & $\mathrm{CO}_{2} \mathrm{Me}$ \\
\hline & 4 & 5 & 6 \\
\hline Empirical formula & $\mathrm{C}_{15} \mathrm{H}_{14} \mathrm{BrIN}_{2} \mathrm{O}_{4}$ & $\mathrm{C}_{16} \mathrm{H}_{16} \mathrm{BrIN}_{2} \mathrm{O}_{4}$ & $\mathrm{C}_{13} \mathrm{H}_{9} \mathrm{BrClIN}_{2} \mathrm{O}_{4}$ \\
\hline$F w$ & 493.09 & 507.12 & 499.48 \\
\hline$T[\mathrm{~K}]$ & 293(2) & $200(2)$ & $295(2)$ \\
\hline space group & $P 22_{1} / c$ & $\mathrm{Pbca}$ & $P 2_{1} / n$ \\
\hline$a[\AA ̊]$ & $12.5205(14)$ & $13.9777(5)$ & $8.0519(6)$ \\
\hline$b[\AA]$ & $17.3525(12)$ & $12.2682(5)$ & $13.4135(7)$ \\
\hline$c[\AA]$ & $8.2809(10)$ & $21.0409(9)$ & $16.0842(12)$ \\
\hline$\alpha\left[^{\circ}\right]$ & 90 & 90 & 90 \\
\hline$\beta\left[^{\circ}\right]$ & $104.962(11)$ & 90 & $100.835(8)$ \\
\hline$\gamma\left[{ }^{\circ}\right]$ & 90 & 90 & 90 \\
\hline$V\left[\AA^{3}\right]$ & $1738.1(3)$ & $3608.1(3)$ & $1706.2(2)$ \\
\hline Z & 4 & 8 & 4 \\
\hline$\rho$ calcd $\left[\mathrm{g} \mathrm{cm}^{-3}\right]$ & 1.884 & 1.867 & 1.944 \\
\hline$\mu\left[\mathrm{mm}^{-1}\right]$ & 4.161 & 4.012 & 4.392 \\
\hline Crystal size $[\mathrm{mm}]$ & $0.30 \times 0.15 \times 0.10$ & $0.30 \times 0.20 \times 0.15$ & $0.30 \times 0.25 \times 0.20$ \\
\hline $2 \Theta$ range $\left[{ }^{\circ}\right]$ & 3.368 to 50.048 & 4.824 to 50.046 & 3.984 to 50.054 \\
\hline Reflections collected & 7071 & 11745 & 6546 \\
\hline
\end{tabular}


Table 1. Cont.

\begin{tabular}{cccc}
\hline Independent reflections & $3064\left[R_{\text {int }}=0.0433\right]$ & $3185\left[R_{\text {int }}=0.0389\right]$ & $3011\left[R_{\text {int }}=0.0592\right]$ \\
Data/restraints/parameters & $3064 / 0 / 211$ & $3185 / 0 / 221$ & $3011 / 0 / 201$ \\
$\mathrm{GOF}^{\mathrm{c}}$ & 1.013 & 1.075 & 1.029 \\
$R_{1}{ }^{\mathrm{a}}$ & 0.0462 & 0.0312 & 0.0556 \\
$w \mathrm{R}_{2} \mathrm{~b}$ & 0.0896 & 0.0668 & 0.1310 \\
Largest diff. peak/hole & $0.39 /-0.67$ & $0.37 /-0.61$ & $0.45 /-0.98$ \\
${\text { [e } \AA^{-3} \text { ] }}_{\text {CCDC number }}$ & 2039136 & 2039137 & 2039138 \\
\hline
\end{tabular}

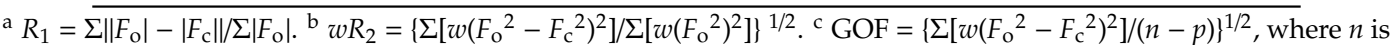
the number of reflections and $p$ is the total number of parameters refined.

\subsection{X-ray Crystallography}

The solid-state structures of the compounds 1-6 were investigated by single crystal X-ray diffraction. According to this study, all the compounds crystallize with one molecule in the asymmetric unit, as depicted in Figure 3. There were no co-crystallized solvent molecules in any of the crystals. The bond distances and angles are summarized in Table S1. This series of 5-iodopyrazoles exhibited a similar molecular structure, their compositions differing only by the nature and position of the phenyl substituents. As a result of the predicted steric hindrance, the molecules were essentially non-planar. The dihedral angles between the 5-iodopyrazole and phenyl rings were in the range 76.4(1)-94.6(3) ${ }^{\circ}$.
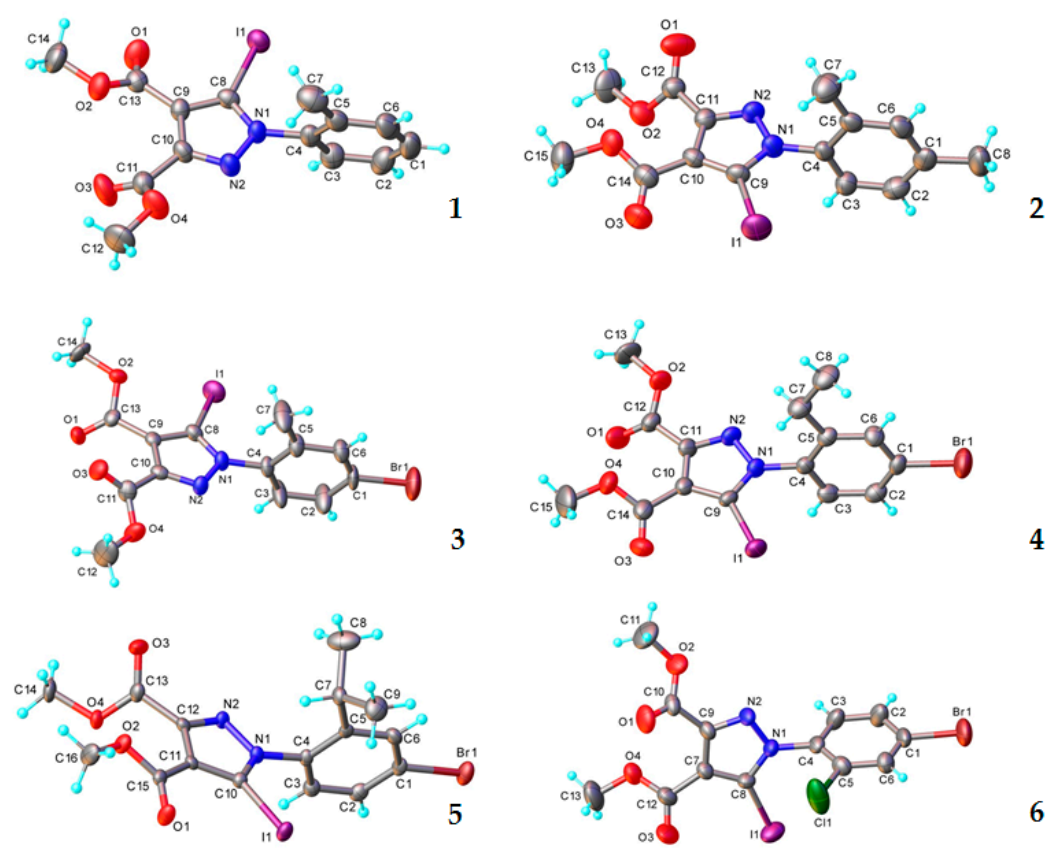

Figure 3. X-ray molecular structures with atom labeling and thermal ellipsoids at the $50 \%$ level for the compounds 1-6.

The analysis of the crystal packing for the compounds investigated revealed a variety of supramolecular architectures, where the intermolecular interactions are driven by the presence of $\mathrm{C}-\mathrm{Br} \cdots \mathrm{O}$ or $\mathrm{C}-\mathrm{I} \cdots \mathrm{O}$ halogen bonding as well as, in the majority of the crystals, by $\mathrm{C}-\mathrm{H} \cdots \mathrm{O}$ hydrogen bonding.

The X-ray diffraction study of compound $\mathbf{1}$ highlighted the iodine atom as being involved in C-I $\cdots$ O halogen bonding towards a carbonyl oxygen atom of an adjacent molecule, which leads to the formation of infinite supramolecular chains, as depicted in Figure 4. 


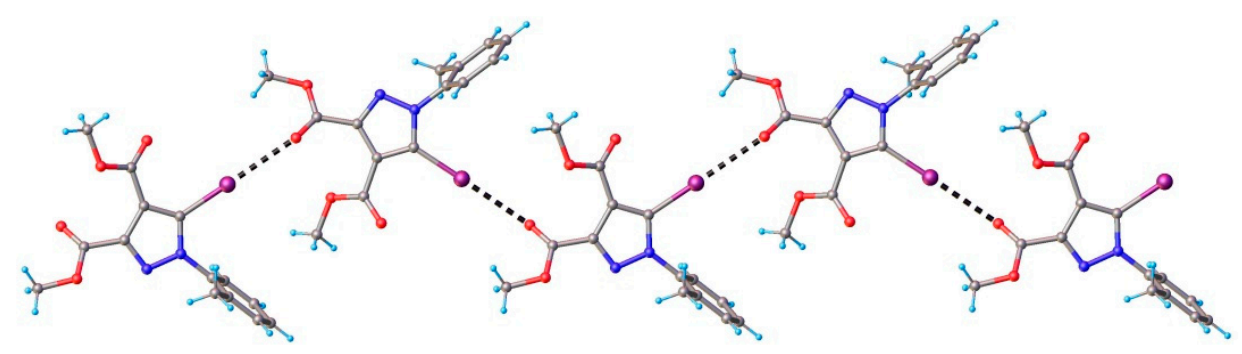

Figure 4. Partial view of the $1 \mathrm{D}$ chain formed through C-I $\cdots$ O halogen bonds in the crystal structure

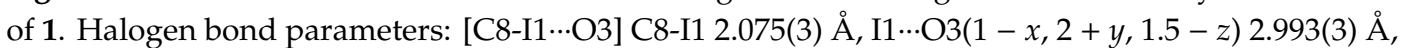
$\angle \mathrm{C} 8 \mathrm{I} 1 \mathrm{O} 3175.2(1)^{\circ}$.

The crystal structure was built up via the parallel packing of discrete 2D layers, as shown in Figure 5. A similar packing of relatively isolated supramolecular layers (Figure 6) was observed in the crystal of compound 2. Compared with compound 1, in 2, each layer was consolidated exclusively by $\mathrm{C}-\mathrm{H} \cdots \mathrm{O}$ intermolecular contacts with appropriate hydrogen bonding parameters. Short intermolecular contacts fulfilling the conditions of halogen bonding were not obvious in the crystal of $\mathbf{2}$ upon preliminary inspection, but an iodine- $\pi$ interaction was highlighted by Hirshfeld surface analysis, which will be discussed later.

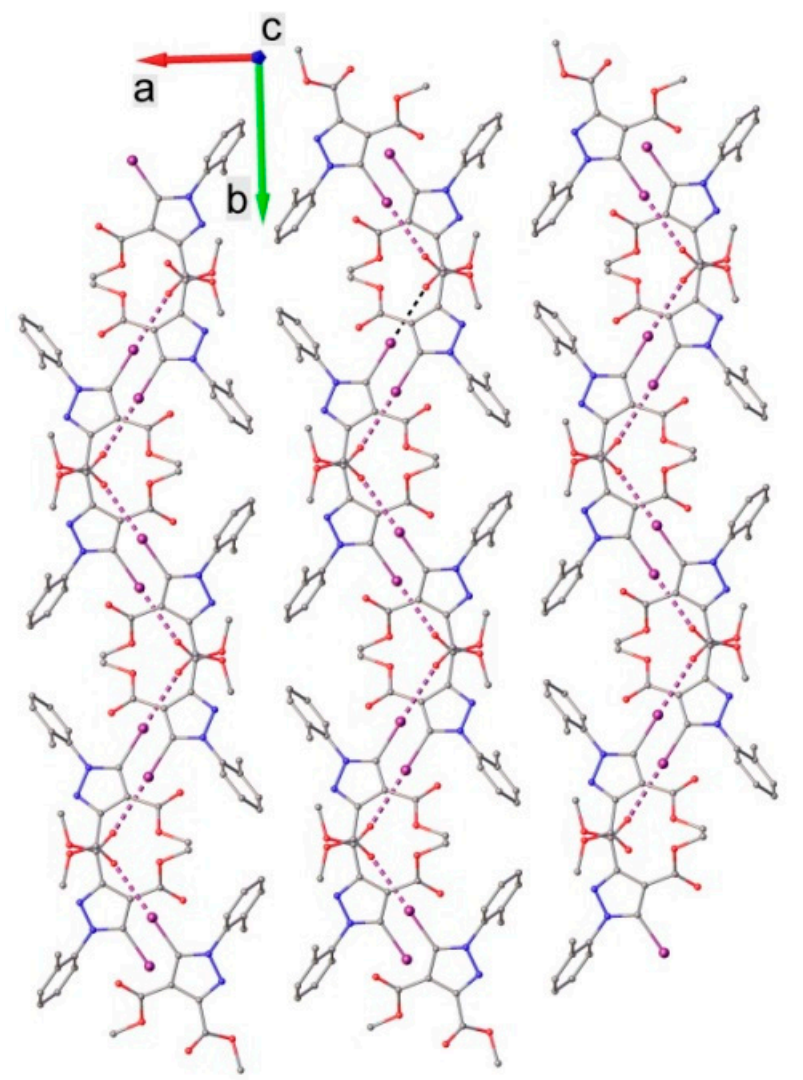

Figure 5. Crystal packing diagram of $\mathbf{1}$ viewed along the $c$-axis. $\mathrm{H}$ atoms are not shown. 

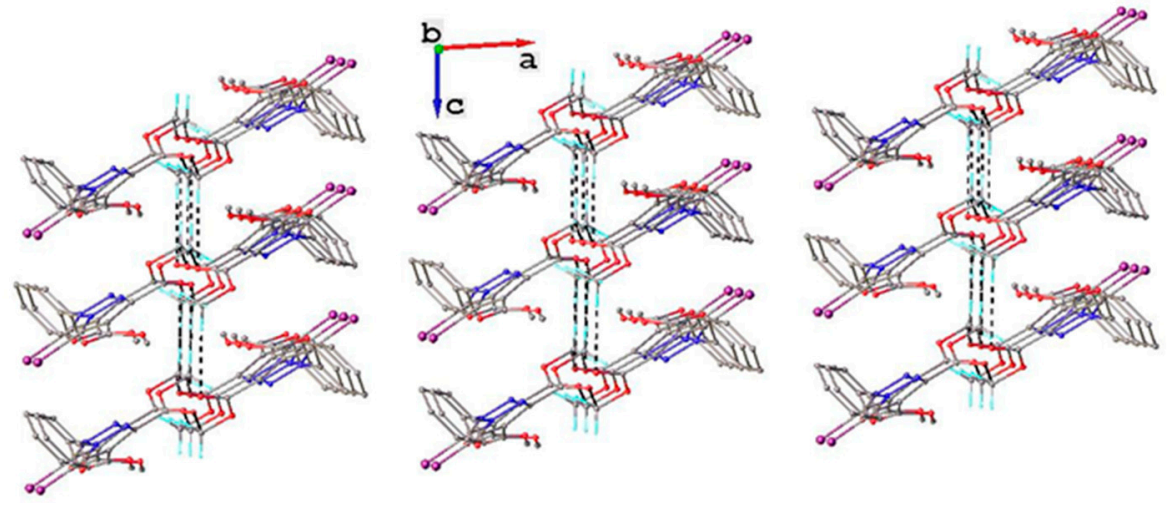

Figure 6. Crystal packing diagram viewed along the $b$-axis for compound 2. Non-relevant $\mathrm{H}$ atoms

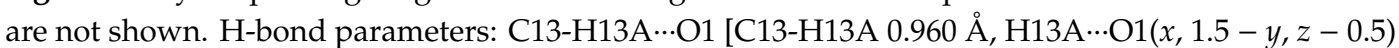

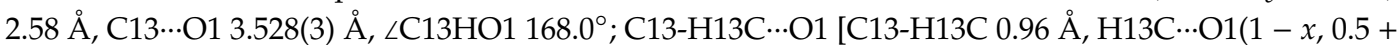
$y, 0.5-z) 2.55 \AA, C 13 \cdots \mathrm{O} 13.465(3) \AA, \angle \mathrm{C} 13 \mathrm{HO} 1160.4^{\circ}$.

As demonstrated by X-ray crystallography, the crystal packing of compound 3 was determined by $\mathrm{C}-\mathrm{Br} \cdots \mathrm{O}$ and $\mathrm{C}-\mathrm{I} \cdots \mathrm{O}$ halogen bonding, as well as by $\mathrm{C}-\mathrm{H} \cdots \mathrm{O}$ hydrogen bonding. The intermolecular halogen bonds are depicted in Figure 7.

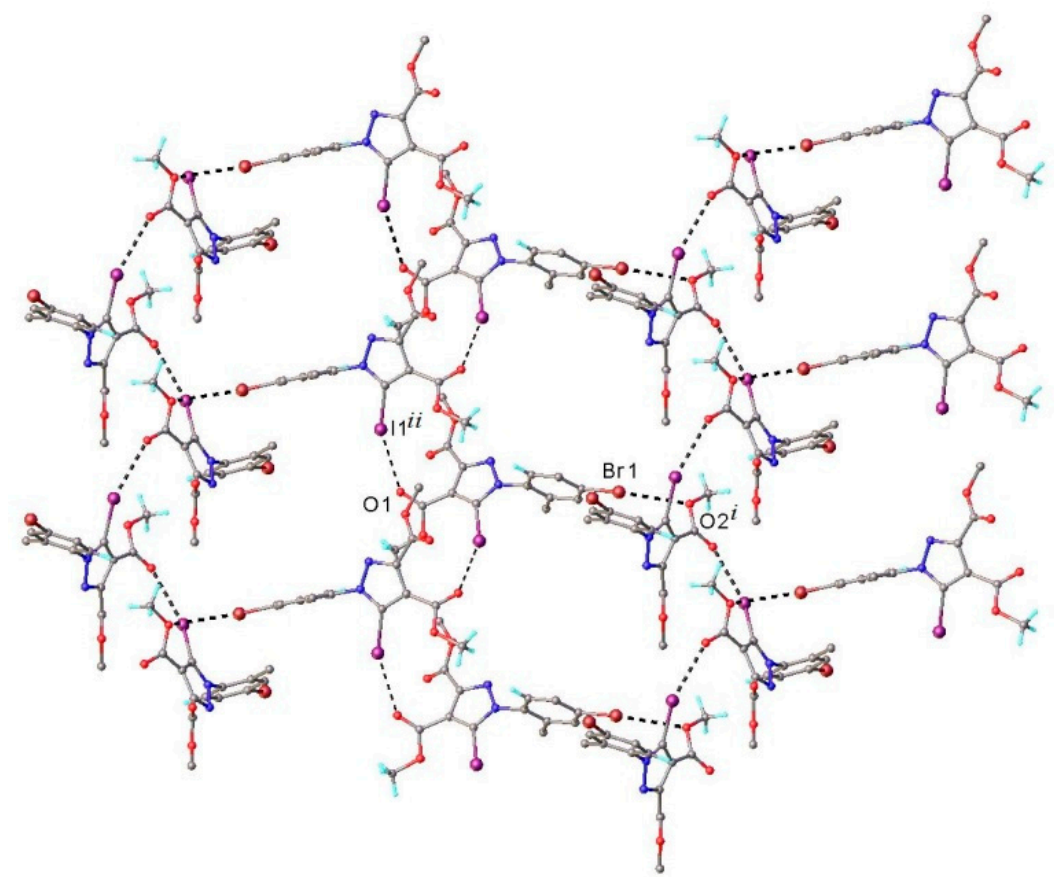

Figure 7. A partial view of 3D network showing C-Br $\cdots \mathrm{O}$ and $\mathrm{C}-\mathrm{I} \cdots \mathrm{O}$ halogen bonding in the crystal

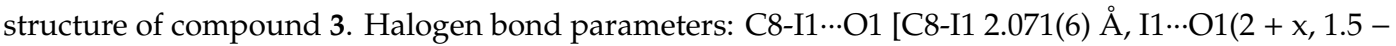

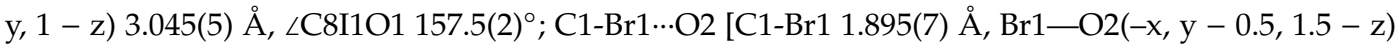
3.251(5) $\AA$, $\angle \mathrm{C} 1 \mathrm{Br} 1 \mathrm{O} 2157.9(3)^{\circ}$.

As could be observed, each molecule of compound 3 was involved in the formation of four halogen bonds with symmetry-related molecules: twice as a donor and twice as an acceptor of halogen. Due to the three-dimensional orientation of the halogen bonding, the molecular units were auto-assembled to form a dense 3D supramolecular network. A view of the 3D architecture is shown in Figure 8. 


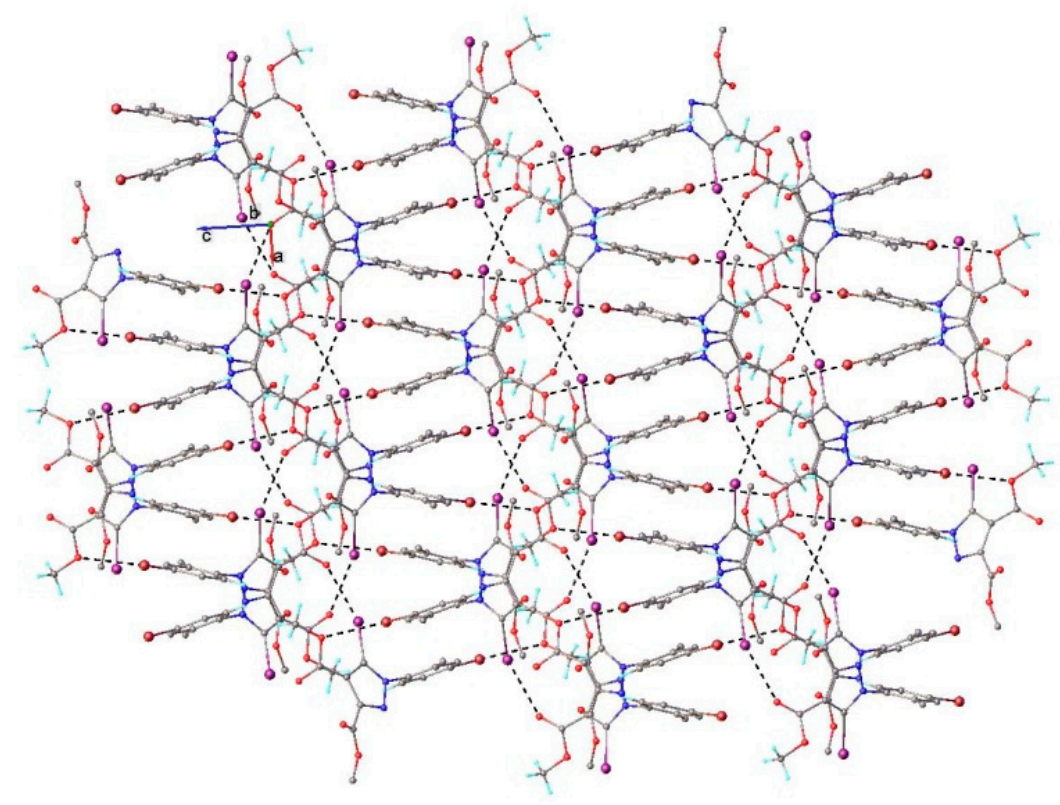

Figure 8. Packing diagram showing the formation of 3D supramolecular architecture in compound

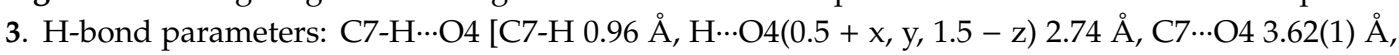

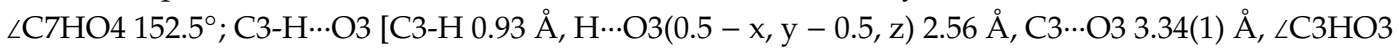

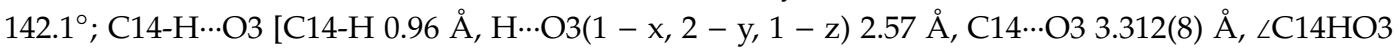
$134.5^{\circ}$.

Additionally, the 3D network was stabilized by an extended system of $\mathrm{C}-\mathrm{H} \cdots \mathrm{O}$ short contacts, which can be interpreted as intermolecular hydrogen bonding. According to the X-ray diffraction study (Table 1$)$, compounds 1 and 4 crystallize in the same space group $\left(P 2_{1} / c\right)$ with similar unit cell parameters. Consequently, due to some level of isostructurality, these compounds exhibited similar crystal packing features. Figure 9 illustrates the influence of C-I $\cdots O$ intermolecular interactions on the linear array arrangement in the crystal of 4 , which closely resembled the supramolecular chain found in the crystal structure of $\mathbf{1}$.

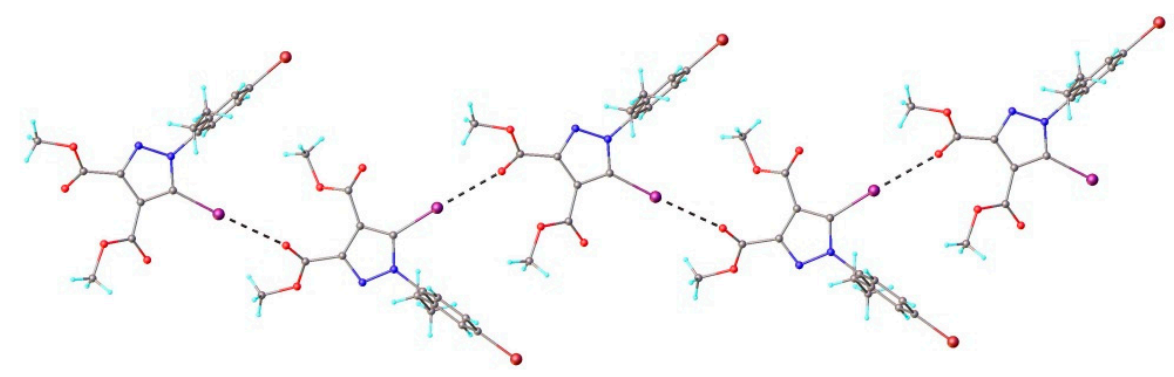

Figure 9. Partial view of the 1D supramolecular chain in the crystal structure of 4 . Halogen bond

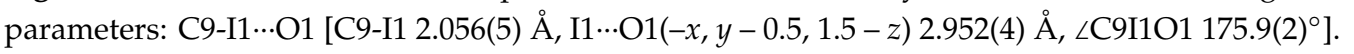

The shortest intermolecular $\mathrm{I} \cdots \mathrm{Br}$ contact which occurred in the crystal of compound 5 was found to be 3.6468(5) $\AA$. As a result, the main crystal structure motif can be characterized as an infinite chain formed by C-I $\cdots$ Br halogen bonding, a view of which is depicted in Figure 10a. The analysis of the crystal packing showed that the chains were further interacting via $\mathrm{C}-\mathrm{H} \cdots \mathrm{O}$ hydrogen bonds, which determined the presence of a tangled three-dimensional supramolecular network. A view of the crystal packing is shown in Figure 10b. As could be observed, the crystal structure was characterized as a parallel packing of $2 \mathrm{D}$ networks, which were interconnected through $\mathrm{C}-\mathrm{I} \cdots \mathrm{Br}$ and $\mathrm{C}-\mathrm{H} \cdots \mathrm{O}$ interlayer interactions. 

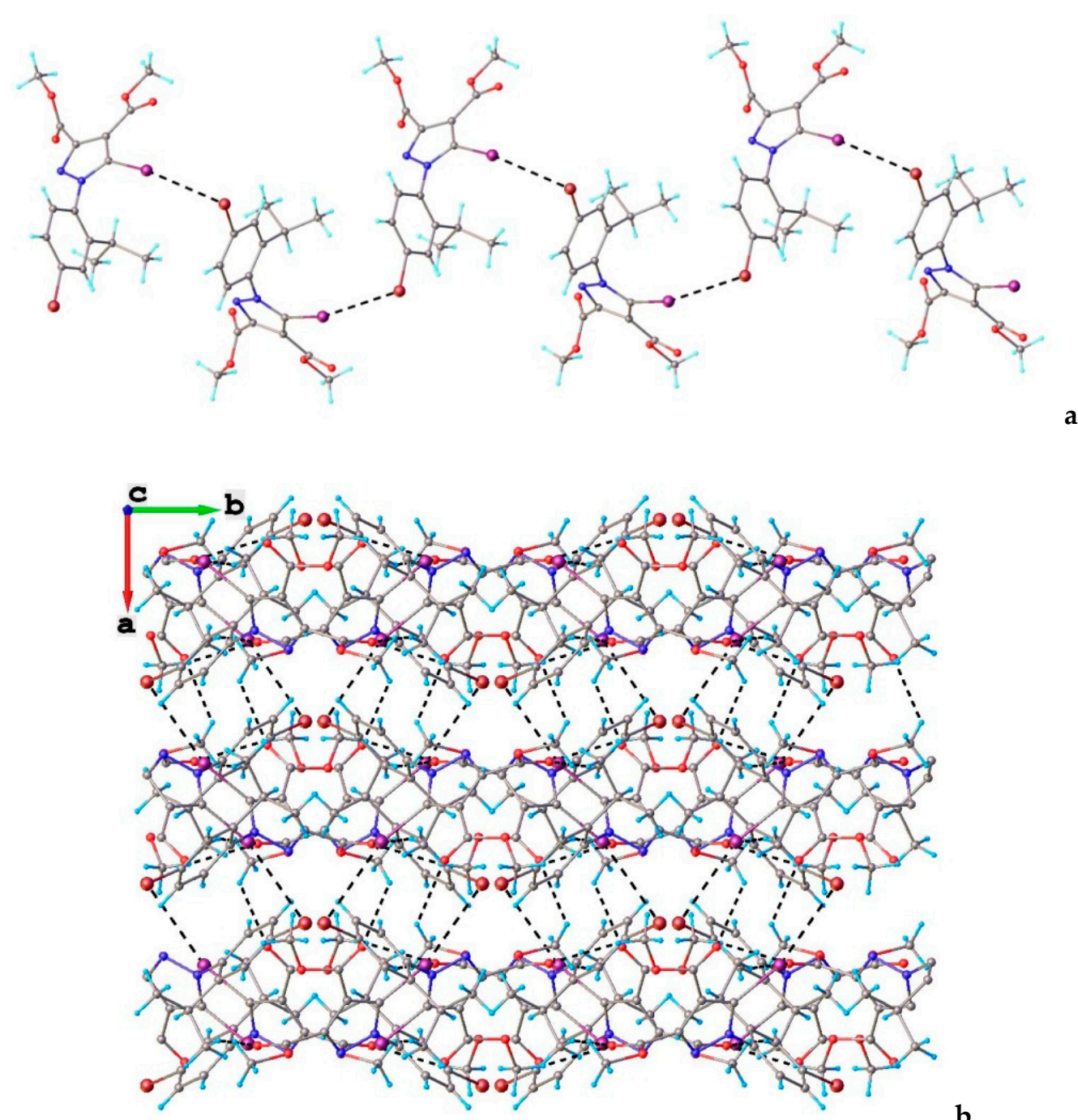

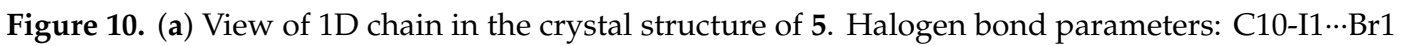

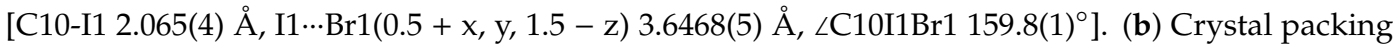

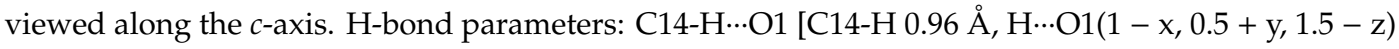

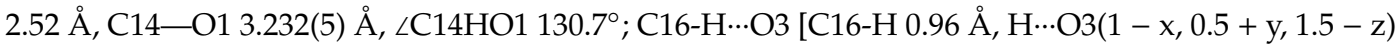

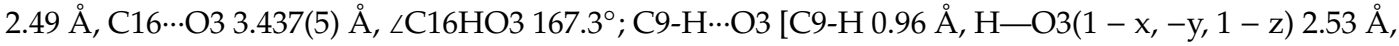
C9...O3 3.462(6) $\AA$, $\angle$ C9HO3 $162.5^{\circ}$.

In the crystal of 6 , the molecules interacted through $\mathrm{C}-\mathrm{Br} \cdots \mathrm{O}$ and a bifurcated $\mathrm{C}-\mathrm{I} \cdots \mathrm{O}$ and $\mathrm{C}-\mathrm{I} \cdot \mathrm{N}$ halogen bonding to form wave-like two-dimensional supramolecular layers, depicted in Figure 11. In turn, $\mathrm{C}-\mathrm{H} \cdots \mathrm{O}$ hydrogen bonds interconnected these layers, thereby generating a three-dimensional architecture (see Figure 11b). 

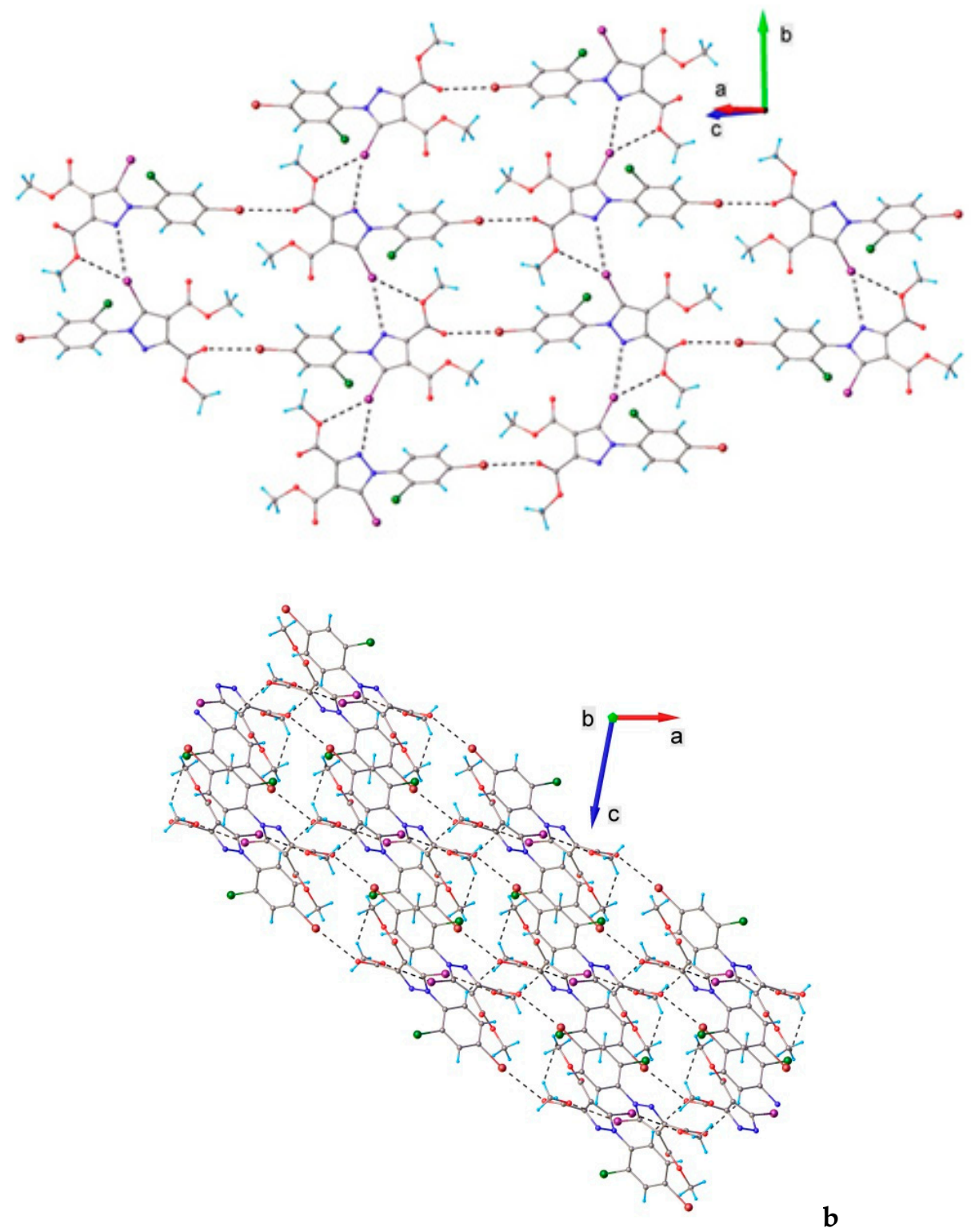

Figure 11. (a) The formation of a $2 \mathrm{D}$ supramolecular layer in the crystal structure of 6 . Halogen

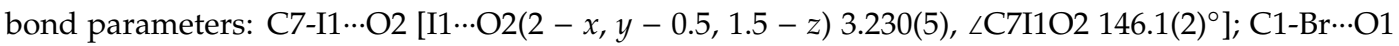

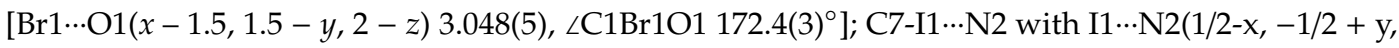
3/2-z) 3.2803(2) $\AA, \angle$ C7I1N2 162.2 . (b) Packing diagram viewed along the $b$-axis. H-bond parameters:

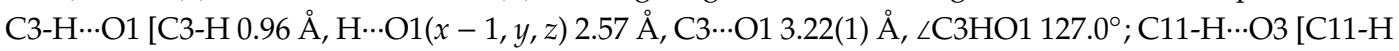
$0.96 \AA, \mathrm{H} \cdots \mathrm{O} 3(1.5-x, 0.5+y, 1.5-z) 2.66 \AA$, C11 ‥ $333.50(1) \AA, \angle \mathrm{C} 11 \mathrm{HO} 3146.1^{\circ}$.

\subsection{Hirshfeld Analysis}

Compound 1. The compound 1 has a methyl group attached to the ortho position of the phenyl ring. As is already known [46,57], substitution of this kind leads to a rotation of the phenyl ring out of the pyrazole plane in order to accommodate the steric hindrance. The most intuitively obvious halogen interaction based on previous observations is generally that between the iodine atom of one molecule and the oxygen atom in an ester group or the available nitrogen atom in the pyrazole ring of another molecule. In this case, molecule 1 presented an intermolecular C-I $\cdots$ O bond between the iodine atom and the $\mathrm{O}$ atom of the $\mathrm{C}=\mathrm{O}$ group at position 3 of the pyrazole ring (Figure 12) in a neighboring molecule. 

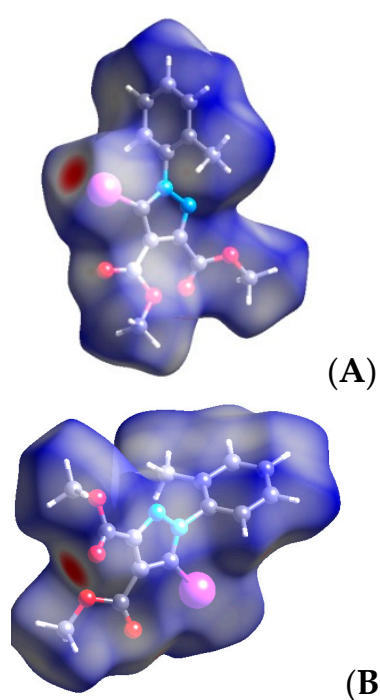

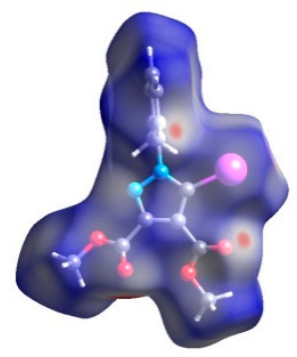

(C)

(B)

Figure 12. Hirshfeld surface of compound 1 showing the red spots corresponding to the C-I $\cdots O$ interactions (A,B) and for hydrogen close contacts (C). Halogen bond parameters: C-I bond length: $2.075 \AA$; I . . O distance: $2.993 \AA$; sum of the vdW radii: $3.5 \AA$ [58]; $\angle \mathrm{C}-\mathrm{I}$. . O : $175.2^{\circ}$.

The Hirshfeld surface presents the strong C-I $\cdots O$ O contact between the iodine and the carbonyl oxygen of the ester attached at C-3 of the pyrazole ring (A, B - red spots). Infinite chains along the $\mathrm{C}-\mathrm{I} \cdots \mathrm{O}$ ran in antiparallel directions, and these were stacked together through $\mathrm{C}=\mathrm{O} \cdots \mathrm{H}$ bonds $(\mathrm{C})$ involving the oxygen in the ester group at $\mathrm{C}-4$ of the pyrazole and $\mathrm{H}-6$ of the phenyl group

Compound 2. By adding a methyl group to the para position of the phenyl ring, one might expect that the newly introduced bulky group would show some influence on the packing of the molecules, and indeed in this case, C-I $\cdots \pi$ dimers (Figure 13) between two inverted molecules were formed. These dimers are held together by hydrogen bonds involving the carbonyl groups of the esters and hydrogen atoms of the phenyl moiety. It has previously been shown that C-I $\cdots \pi$ dimers of this kind are not uncommon for phenylpyrazoles [46,57].

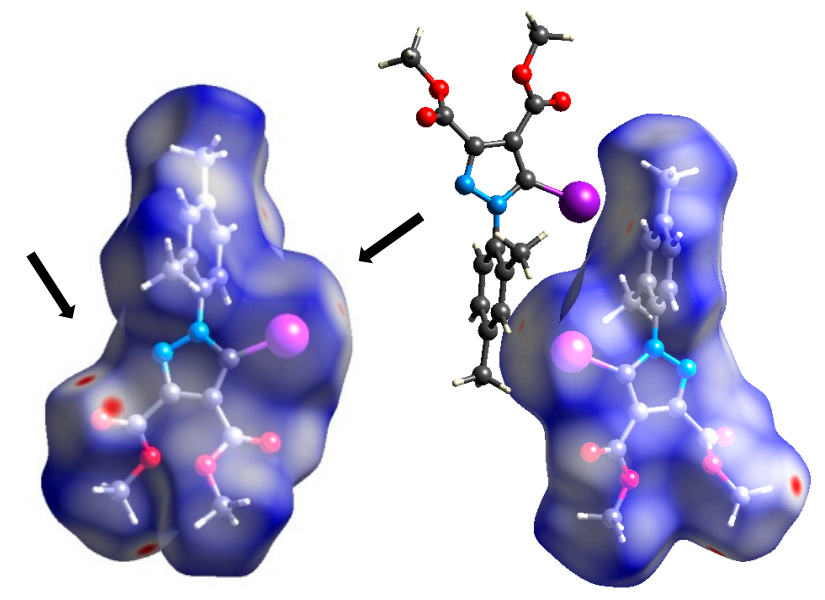

(A)

(B)

Figure 13. Hirshfeld surface of compound 2 and the exemplified dimer formed by the C-I $\cdots \pi$ bond: (A) close contacts as red spots on the Hirshfeld surface; (B) exemplified dimer formed by the two inversed molecules of 2 generated by the $\mathrm{C}-\mathrm{I} \cdots \pi$ contact. Halogen bond parameters: C-I bond length: $2.071 \AA$; I . . Cg distance: $3.580 \AA$; (sum of the vdW radii: $3.68 \AA$ [58]; $\angle \mathrm{C}-\mathrm{I} \cdots \mathrm{Cg}$ : $171.3^{\circ}(\mathrm{Cg}$ is the centroid of the bond formed by $\mathrm{C}-3$ and $\mathrm{C}-4$ of the phenyl ring). 
The Hirshfeld surface presents the short contacts specific to a C-I $\cdots \pi$ interaction and the strong hydrogen bond contacts (two red spots on the carbonyl oxygen marking a bifurcated $\mathrm{O} \cdots \mathrm{H}$ bond). Of course, one might say that such dimers can be formed in order to minimize the energy in the crystalline lattice, but the contribution of the C-I $\cdots \pi$ interaction is clear and the presence of the $\sigma$-hole of the iodine stabilizes such a dimeric structure. The nature of the $\mathrm{C}-\mathrm{I} \cdots \pi$ bond was assessed taking into account the directionality of the bond which clearly indicates a $\sigma$-hole interaction, in spite of a $\pi$-hole interaction with the lone-pair electrons of the iodine [35]. Additionally, the C-I $\cdots \pi$ contact could be characterized as an over-the-bond (or above-the-bond) type.

Compound 3. By replacing the methyl group in the para position of the phenyl ring with a $\mathrm{Br}$ atom, our expectation was that the $\mathrm{Br}$ atom with its $\sigma$-hole would show availability for halogen bonding. Both esters on the pyrazole ring engaged in hydrogen bonds forming dimers as depicted in the previous section.

These dimers were held together by strong C-I $\cdots \mathrm{O}(\mathrm{A}, \mathrm{B})$ bonds with the ester carbonyl at C-4 of the pyrazole. The interesting fact is that $\mathrm{C}-\mathrm{Br} \cdots \mathrm{O}$ halogen bonds were also present with the -Oatom in the same ester moiety (A, C), and this is what we expected to observe by introducing a new halogen atom in the molecule. The Hirshfeld surface depicts very well the relevant contacts for these two halogen bonding patterns (Figure 14).

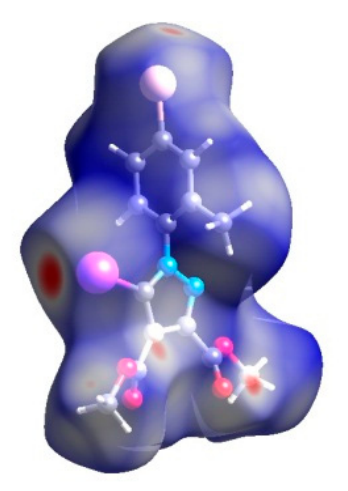

(A)

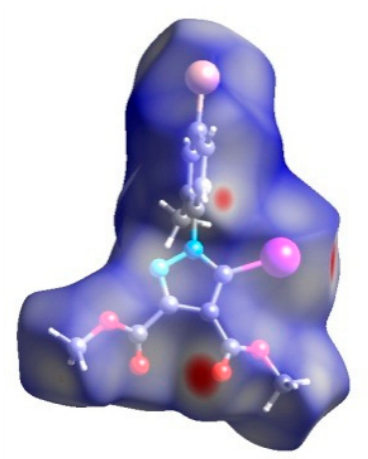

(B)

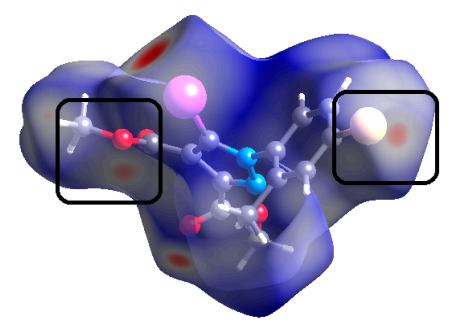

(C)

Figure 14. Hirshfeld surface of compound 3 showing the significant halogen bond contacts: $(\mathbf{A}, \mathbf{B})$ two red spots on the Hirshfeld surface in the fornt of I and $\mathrm{O}$ atoms representing the $\mathrm{I} \cdots \mathrm{O}$ contacts; $(\mathbf{A}, \mathbf{C})$ the red spot in fornt of the $\mathrm{Br}$ atom and the $-\mathrm{O}$ - atom for the $\mathrm{Br} \cdots \mathrm{O}$ contact. Halogen bond parameters: C-I bond length: $2.071 \AA$; I $\cdots$ O distance: $3.045 \AA$; sum of the vdW radii: $3.5 \AA$ [58]; $\angle \mathrm{C}-\mathrm{I} \cdots \mathrm{O}: 157.5^{\circ}$. Halogen bond parameters: C-Br bond length: $1.895 \AA$; Br $\cdots$ O distance: $3.251 \AA$; sum of the vdW radii: $3.37 \AA$ [58]; $\angle \mathrm{C}-\mathrm{Br} \cdots \mathrm{O}: 157.9^{\circ}$.

Compound 4. For the compound 4, the intention was to insert, instead of the more bulky methyl group, a less sterically contributive group such as an ethyl group, which is more flexible. The $\mathrm{Br}$ atom was kept in the para position. Interestingly, compound $\mathbf{4}$ showed a similar pattern to compound $\mathbf{1}$ (Figure 15). 


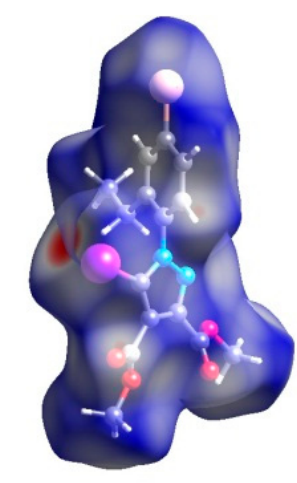

(A)
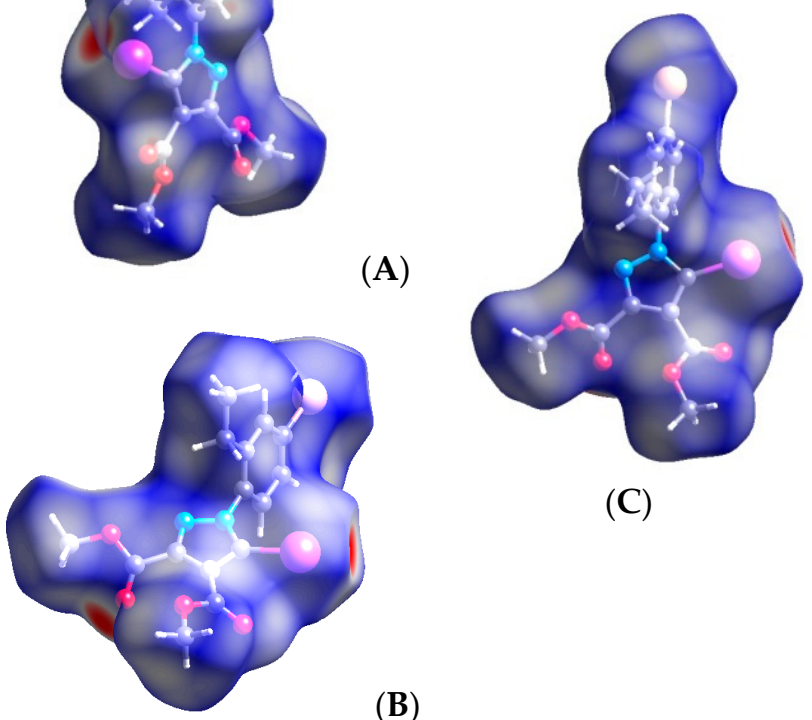

(C)

(B)

Figure 15. Hirshfeld surface of compound 4 showing the C-I $\cdots$ O contact red spots (A-C). Halogen bond parameters: C-I bond length: $2.056 \AA$; I . . O distance: $2.951 \AA$; sum of the vdW radii: $3.5 \AA$ [58]; $\angle \mathrm{C}-\mathrm{I} \cdots \mathrm{O}$ : $175.9^{\circ}$.

One can observe the similarity of the C-I $\cdots \mathrm{O}$ patterns in compounds 4 and $\mathbf{1}(\mathrm{A}, \mathrm{B})$. The $\mathrm{Br}$ atom appears not to be involved in any interactions, although the distance $\mathrm{Br} \cdots \mathrm{O}(3.439 \AA$ ) between $\mathrm{Br}$ atom and -O- oxygen in the ester moiety attached to $\mathrm{C}-3$ of the pyrazole ring is very close to the sum of the vdW radii. However, the angle C-Br $\cdots \mathrm{O}$ of $\sim 124^{\circ}$ would not agree with the directionality of the halogen bond. As far as halogen bonding is concerned, the Hirshfeld analysis did not show any relevant contact for the $\mathrm{Br}$ atom, but only for the iodine atom. The similarity of the structural arrangements in the two compounds is depicted in Figure 16, showing the infinite C-I $\cdots$ O chains.
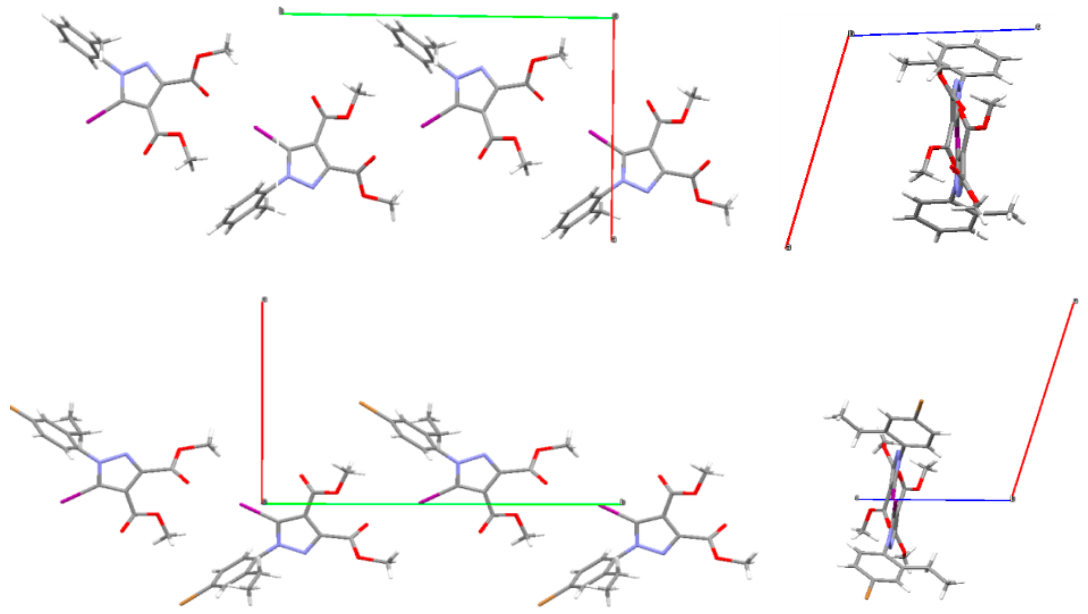

Figure 16. Infinite chains generated by the C-I $\cdots O$ interactions along the b-axis (green colour) in 1 (top) and 4 (bottom) showing similar crystal packing.

Compound 5. By replacing the ethyl group with a very bulky isopropyl moiety, we could expect strong C-I $\cdots N$ interaction, as we had encountered with a previously reported compound [46] lacking the $\mathrm{Br}$ atom at the para position of the phenyl ring. However, the $\mathrm{Br}$ atom behavior in $\mathbf{5}$ ran contrary to 
expectations, and we observed instead a type II halogen-halogen interaction between the iodine atom of one molecule and the bromine atom of another molecule. In this case, iodine participated through its bigger sigma-hole, while the $\mathrm{Br}$ atom acted as the nucleophilic partner of the halogen bond. The type II halogen bond is also shown on the Hirshfeld surface at the correct positions (A, B). The bond distance and directionality of the short contact between the $\mathrm{Br}$ atom and the I atom are typical for a type II electrostatically driven halogen-halogen interaction (Figure 17).

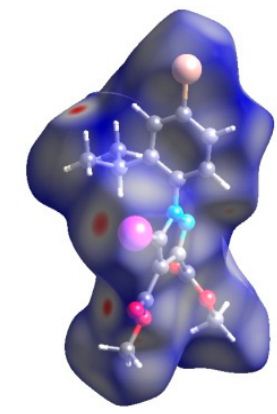

(A)
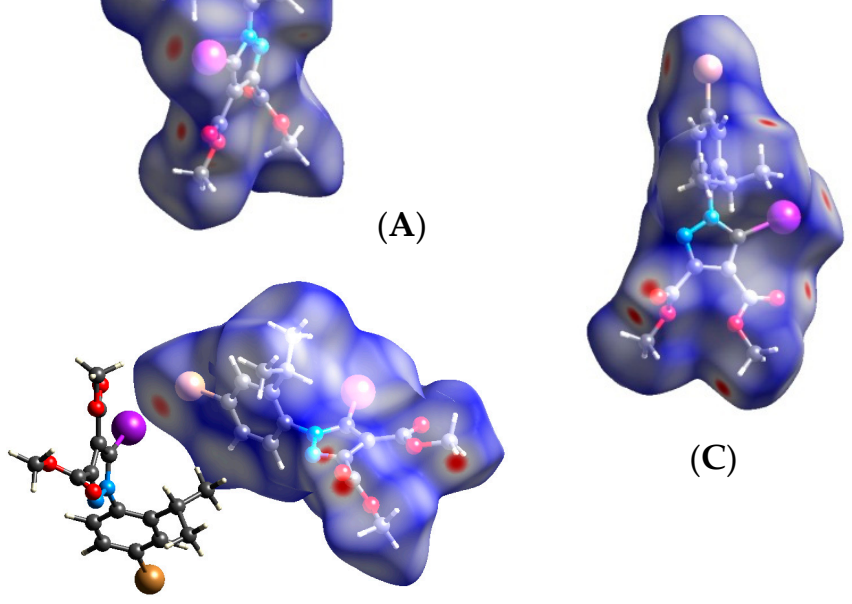

(C)

(B)

Figure 17. Hirshfeld surface of compound 5 showing the C-I $\cdots \mathrm{Br}$ type II halogen-halogen bond: (A,B) Hirshfeld surface presenting the halogen-halogen interaction of type II between the I and $\mathrm{Br}$ atoms; (C) Red spots on the Hirshfeld surface representing the hydrogen bond contacts. Halogen bond parameters: C-I bond length: $2.065 \AA$; C-Br bond length: $1.906 \AA$; I ․ Br distance: $3.647 \AA$; sum of the vdW radii: $3.83 \AA$ [58]; $\angle \mathrm{C}-\mathrm{I} \cdots \mathrm{Br}: 159.8^{\circ} ; \angle \mathrm{C}-\mathrm{Br} \cdots \mathrm{I}$ : $96.7^{\circ}$.

As expected, the Hirshfeld surface shows also the red spots on the oxygen atoms in the esters which are involved in hydrogen bonds.

Compound 6. The most interesting structure was obtained by replacing the ortho alkyl substituents with a chlorine atom. The small chlorine atom did not show potential for halogen bonding but instead formed $\mathrm{C}-\mathrm{H} \cdots \mathrm{Cl}$ hydrogen bonds involving the methyl group of one ester moiety. This feature evidently rendered molecules of 6 unable to mimic the structural arrangements of the previously described compounds, and in fact, infinite anti-parallel chains of molecules held together via C-H..O bonds were formed instead.

These chains were linked by bifurcated iodine-nitrogen and iodine-oxygen bonds (Figure 18A,B). The Hirshfeld surface depicts all the halogen contacts. Another unexpected but noteworthy observation was the occurrence of the C-Br $\cdots \mathrm{O}$ interaction (Figure $18 \mathrm{C}$ ). Thus, apart from the interlayer $\mathrm{C}-\mathrm{H} \cdots \mathrm{Cl}$ hydrogen bond made by the chlorine atom, we can conclude that in this case, the halogen bonding was clearly the driving force of the crystal packing. 

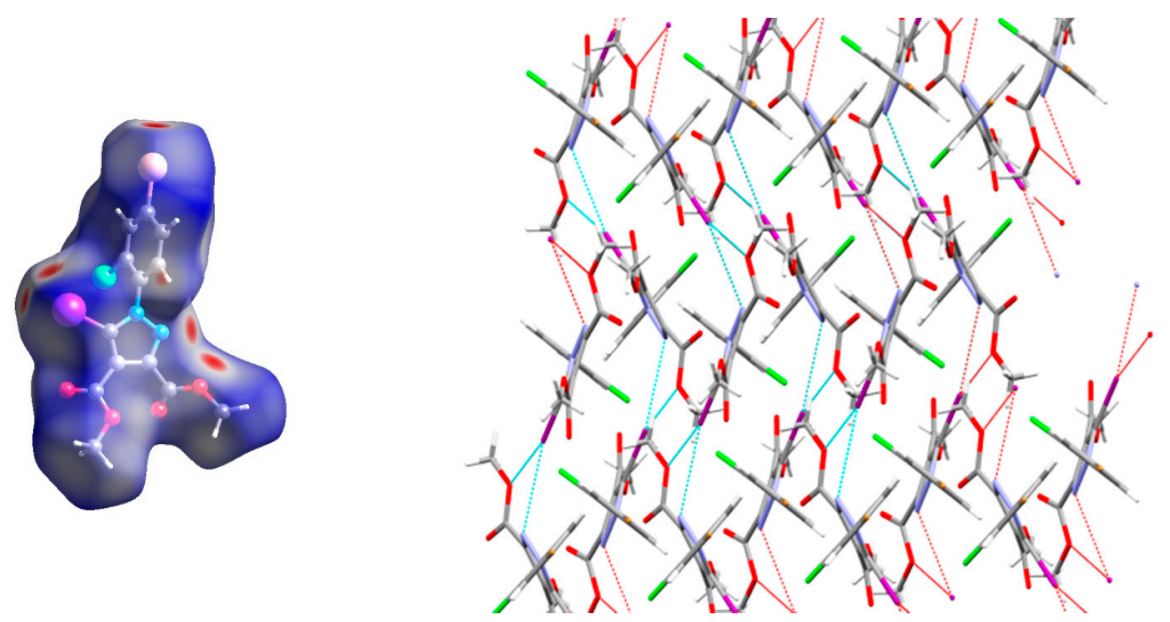

(A)

(B)

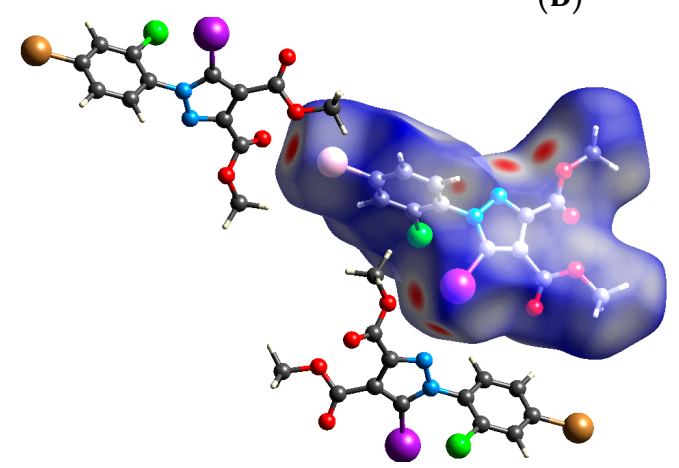

(C)

Figure 18. Hirshfeld surface of compound 6 showing relevant halogen contacts: (A) The red spots corresponding to the bifurcated I $\cdots \mathrm{O}$ and I $\cdots \mathrm{N}$ contacts; (B) Cristal packing presenting the bifurcated iodine bond; (C) Hirshfeld surface presenting both iodine and bromine atoms involved in halogen contacts. Halogen bond parameters: C-I bond length: $2.062 \AA$; I . O distance: $3.230 \AA$; I . N distance:

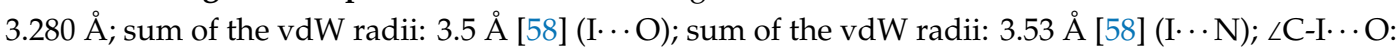
$146.1^{\circ} ; \angle \mathrm{C}-\mathrm{I} \cdots \mathrm{N}: 162.2^{\circ}$. Halogen bond parameters: C-Br bond length: $1.897 \AA$; $\mathrm{Br} \cdots \mathrm{O}$ distance: $3.048 \AA$; sum of the vdW radii: $3.37 \AA$ [58]; $\angle \mathrm{C}-\mathrm{Br} \cdots \mathrm{O}: 172.4^{\circ}$.

The fingerprint plots (Table 2) show a summary of all the molecular interactions which were extracted from the Hirshfeld surface. They represent a "heatmap" of the frequencies of specific interactions between the atoms in the molecules. This suggests a more qualitative rather than a quantitative aspect of the interactions. The most frequent contacts are $\mathrm{H} \cdots \mathrm{H}$ accounting from $30 \%-40 \%$ of the total interactions. The I $\cdots \mathrm{O}$ interactions account for the most frequent (5.5\%) in compound 1 compared to 5, which presents the lowest I...O interactions (2\%) (F 2-bar chart). Additionally, the gradient from blue to green on the fingerprint plot shows that in $\mathbf{1}$ not only the contact distances are small, but also the atoms share a greater percentage of the surface. Table S2 presents the fingerprint plots of the most relevant interactions. 
Table 2. Fingerprint plots of compounds 1-6 showing the most important interactions: halogen interactions and hydrogen bonds.

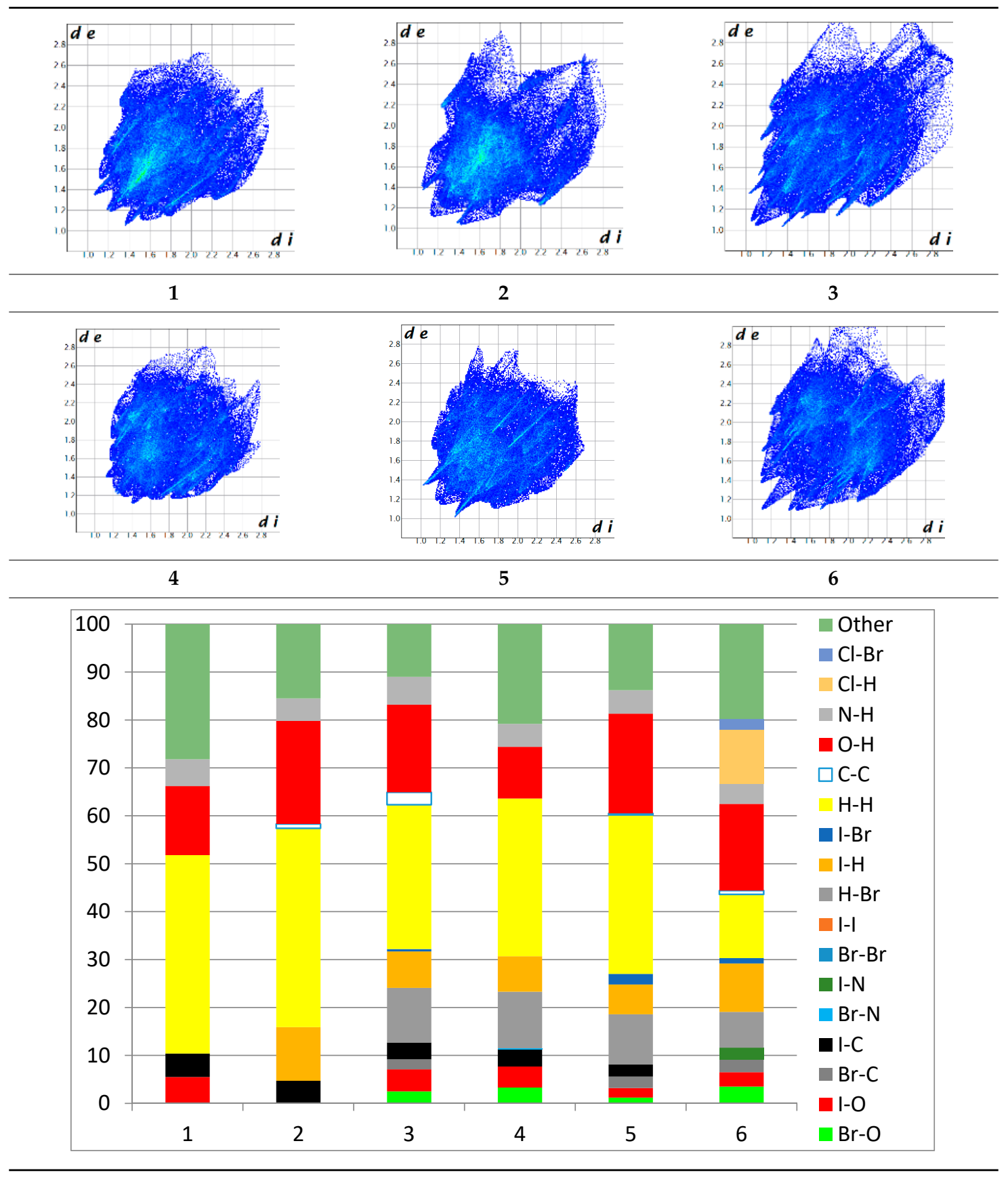

Hydrogen bonds are among the most important interactions, and they were rather frequent and presented a lower percentage only for compounds $\mathbf{1}$ and $\mathbf{4}$, which confirms the similarity of the two compounds, suggesting that not necessarily the $\mathrm{Br}$ atom but the ethyl group could be of greater importance in directing the crystalline growth, the less hindered rotation giving new possibilities of molecules to pack together.

An interesting outcome observed from the fingerprint plot was that compound $\mathbf{1}$ presented a similar percentage for the I $\cdots$ C interactions to compound 2 (4.9\% vs. $4.7 \%)$. First, this may appear intriguing, but the Hirshfeld analysis in shape index mode could lead to the interpretation of an interaction between the lone pair electrons of the iodine atom and the pyrazole ring (Figure 19), although the contact distance was slightly higher than the sum of the vdW radii of the iodine and 
carbon atoms, and this was also the case for compound 4. The two compounds, $\mathbf{1}$ and 2, presented a similar degree of I...C interactions to that in compound 3, and the presence of such interactions even in a low percentage highlights the role of the bulky iodine atom in stabilizing the crystal packing.

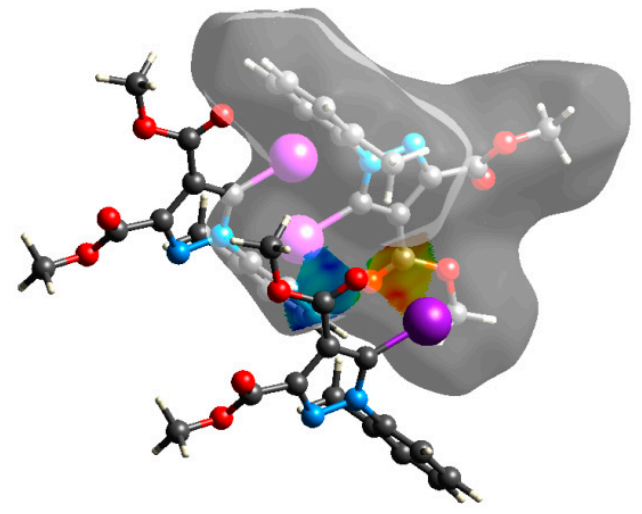

Figure 19. Shape index Hirshfeld surface of compound 1 with the complementary surfaces indicating a possible $\pi$-hole interaction [35].

\subsection{Quantum Computations}

The magnitude of the $\sigma$-holes for the halogen atoms was measured for the compounds 1-6 using G09 program suite [59], having as starting point the structures obtained by single crystal $\mathrm{X}$-ray diffraction. Due to the fact that the hydrogen atoms were not located accurately by $\mathrm{X}$-ray diffraction, their position was optimized at the B3LYP-D3/dgdzvp level $[60,61]$ with the vdW dispersion correction [62]. The DGDZVP basis set is sufficiently accurate for all atomic species, without the need for any pseudopotential [63]. The electrostatic potential V(r) created by the electrons and nuclei of the atoms at any point $r$ was proven to be an accurate approach for the interpretation and quantification of the non-covalent interactions. For this reason, the $\mathrm{V}(\mathrm{r})$ was generated on the molecular surface, defined as $0.001 \mathrm{e} \mathrm{Bohr}^{-3}$ (a. u.) contour of the electronic density. This is a low electron density envelope generated in the range of the atomic vdW radii, defined by Bader et al. to be meaningful for non-covalent interactions [60]. Electrostatic surface potential (ESP) was evaluated using the B3LYP-D3/def2tzvp basis set [64]. The maximum values of the electronic potential on the halogen atom (local maximum) are referred to as $\mathrm{V}_{\mathrm{s}, \max }[34,37]$. Table 3 presents the ESPs of compounds $\mathbf{1}-\mathbf{6}$ rendered in the interval -0.001 and +0.001 a.u. and the corresponding values of $V s$, max which represent the maximum value on the halogen atom $\sigma$-hole.

The molecules 1-6 presented relatively similar values for the $\sigma$-hole $V_{\mathrm{s} \text {, max }}$ magnitudes which could be categorized as medium to high, giving to these compounds high XB donor affinity comparable to the $\sigma$-hole of iodobenzimidazoles and other arylpyrazoles for which similar halogen bonding models were encountered [46,65]. The compounds $\mathbf{1}$ and $\mathbf{2}$ lacking a withdrawing group/atom on the aryl ring, had a smaller $\mathrm{V}_{\mathrm{s} \text {, max }}$ compared to the compounds that had a $\mathrm{Br}$ atom at the para position on the aryl fragment. Therefore, the electron withdrawing substituent showed some influence on the positive magnitude of the iodine $\sigma$-hole which was placed at a relatively large distance from the iodine atom, although through conjugation, it can influence it. On the other hand, the $\mathrm{Cl}$ atom from structure 6 placed on the same aryl ring in the meta position with respect to the $\mathrm{Br}$ atom seemed to show no contribution in increasing the $\mathrm{V}_{\mathrm{s} \text {, max }}$ value. However, it seems that the chlorine atom influenced the $\mathrm{V}_{\mathrm{s} \text {, max }}$ of the $\mathrm{Br}$ atom compared to the alkyl substituents, this being the largest among all the four compounds bearing a $\mathrm{Br}$ atom attached to the aryl fragment. 
Table 3. The electrostatic surface potential (ESP) of 1-6, mapped over 0.001 a.u. showing the $\sigma$-hole of the iodine and bromine atoms.

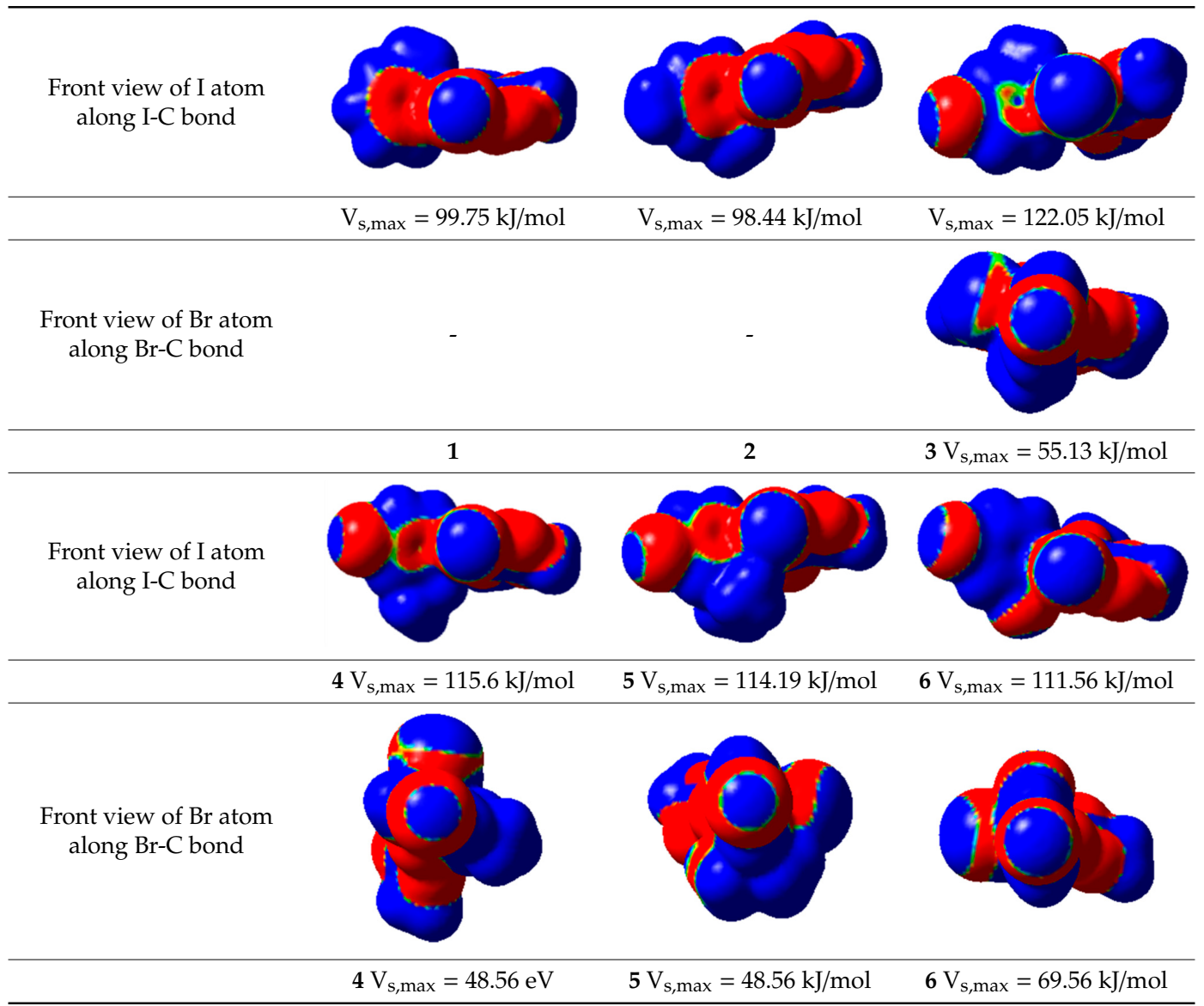

The interaction energies between the molecules involved in halogen bonds (Table 4) were calculated at the same level of theory as for the ESP contours, according to the classical formula:

$$
\Delta \mathrm{E}_{\mathrm{int}}=\mathrm{E}_{\text {dimer }}-\mathrm{E}_{\text {monomer1 }}-\mathrm{E}_{\text {monomer2 }}+\mathrm{BSSE}
$$

where $\mathrm{E}_{\text {dimer, }} \mathrm{E}_{\text {monomer1 }}, \mathrm{E}_{\text {monomer2 }}$ are the DFT energies calculated at the B3LYPD3/Def2tzvp level, and BSSE is the correction calculated at the same level of theory.

Table 4. Halogen bond interaction dimers and their calculated energies.

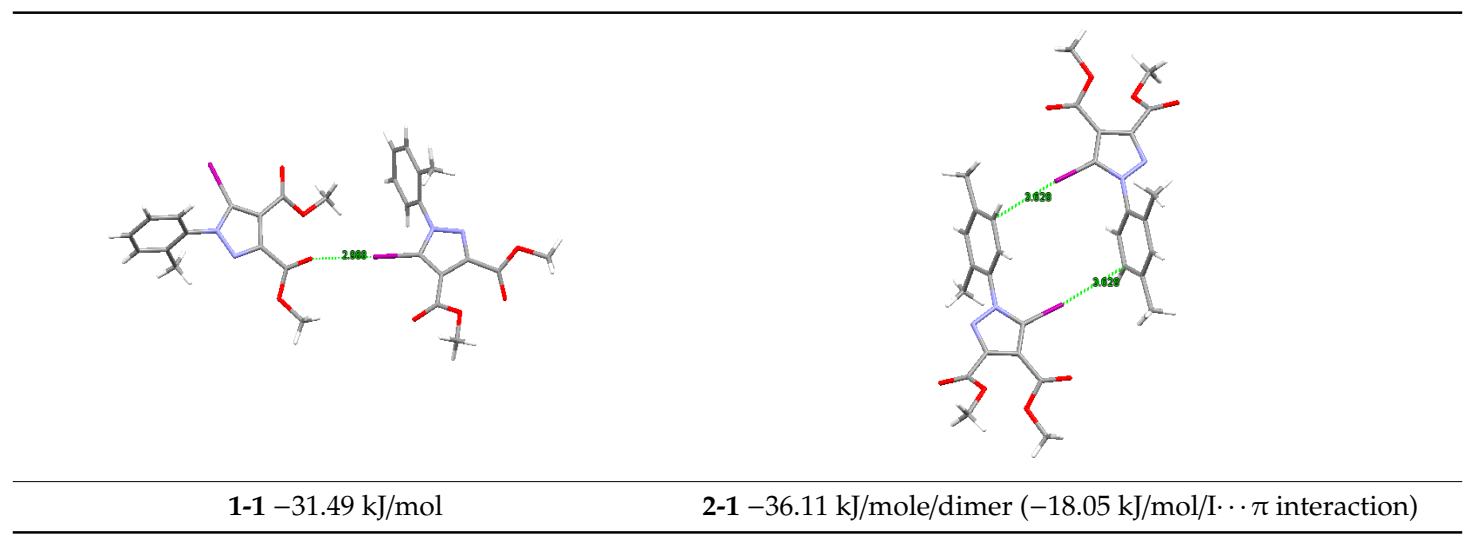


Table 4. Cont.

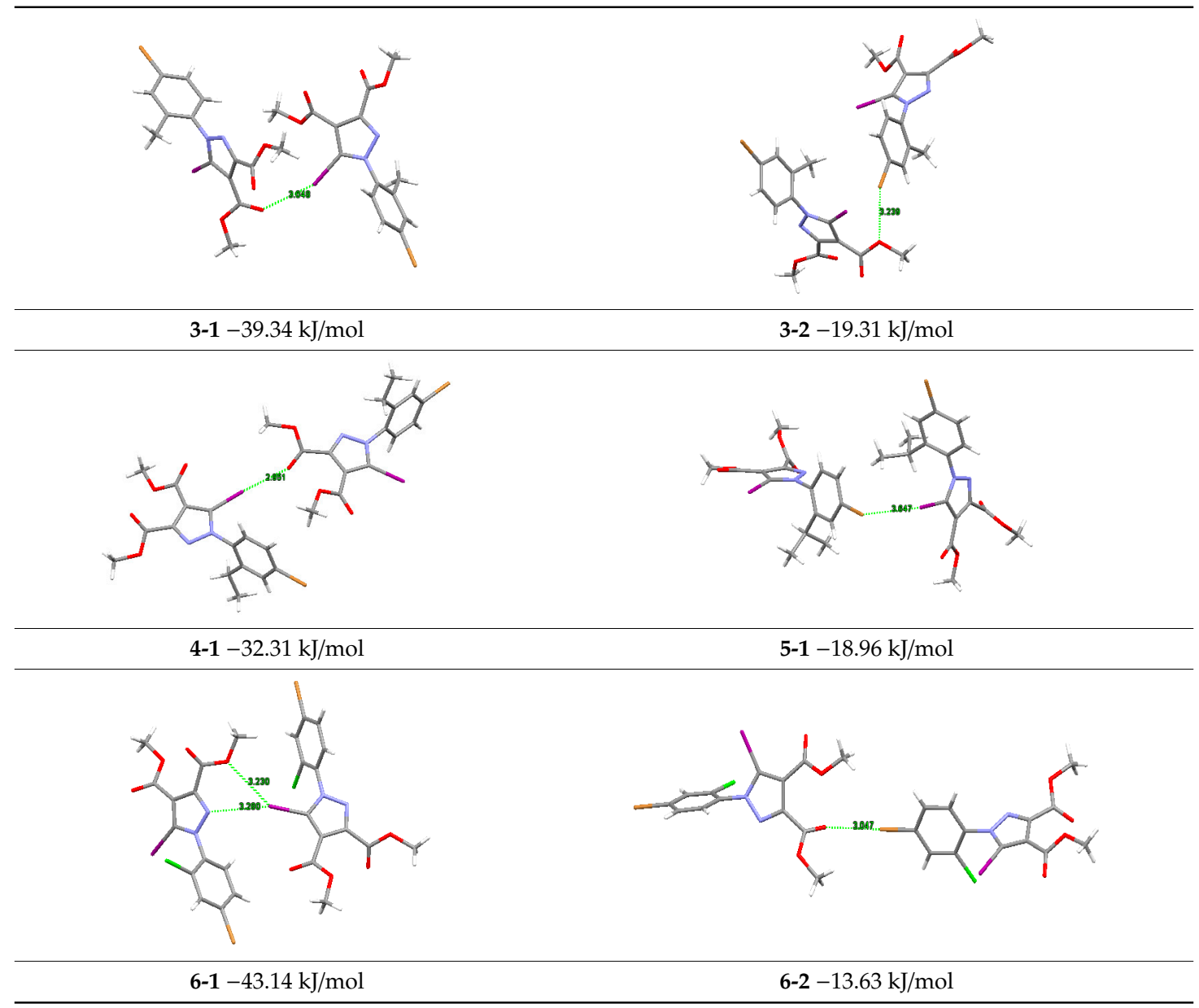

Analyzing the theoretical interaction energies, the trends varied linearly with the values of the $\sigma$-hole strength (iodine gave stronger interactions than bromine due to the smaller electropositive value of the $\mathrm{Br} \sigma$-hole). Therefore, the strongest interactions were of the type $\mathrm{C}-\mathrm{I} \cdots \mathrm{O}$ with $\approx 32 \mathrm{~kJ} / \mathrm{mole}$ in 1-1 and 4-1. Much weaker interactions (almost half of the halogen $\mathrm{I} \cdots \mathrm{O}$ intermolecular bond strengths) were of the following types and strengths: C-I $\cdots \mathrm{Br}$ of $5-1(-18.96 \mathrm{~kJ} / \mathrm{mole}), \mathrm{C}-\mathrm{Br} \cdots \mathrm{O}$ of 3-2 $(-19.31 \mathrm{~kJ} / \mathrm{mole})$ and C-Br $\cdots$ O of dimer2 of $6(-13.63 \mathrm{~kJ} / \mathrm{mole})$. The C-I $\cdots \pi$ interaction in the 2-1 structure was also weaker $(-18.05 \mathrm{~kJ} /$ mole $)$ than C-I $\cdots$ O because of the lower electronegativity of the $\pi$-electron cloud. On the other hand, in addition to the halogen bonds, hydrogen bonds remain important interactions and, for comparison, values of their interaction energies were calculated in 1S and 5S (Table S3). For example, for the interaction energies in the dimers $\mathbf{1 S}$ and $5 \mathrm{~S}$ generated by hydrogen bonds, the interaction energy values were -27.45 and $-18.29 \mathrm{~kJ} / \mathrm{mole}$ (for one single $\mathrm{C}-\mathrm{H} \cdots \mathrm{O}$ interaction), thus making the values of the energy interactions in the case of halogen bonds to be considered rather strong.

\section{Conclusions}

In conclusion, we have shown that halogenated 1-phenylpyrazoles present interesting features regarding the halogen bond, which can be further evaluated to gain more insight into the predictability of the halogen bond. Six crystals were investigated and showed different halogen bond patterns. The halogen contacts presented strong similarity with the literature regarding contact distances and directionality. Furthermore, by introducing a $\mathrm{Br}$ atom on the phenyl ring, it was shown that it too could be involved in halogen bonding. Iodinated pyrazoles are important benchmarks in investigating 
the nature of the halogen bond and could also lead to a deeper understanding of halogen bonding of analogous residues in macromolecules.

Supplementary Materials: Supplementary Materials: The following are available online at http://www.mdpi. com/2073-4352/10/12/1149/s1, Table S1: Bond distances and angles, Table S2. Fingerprint plots showing the most important intermolecular interactions: halogen bonds and hydrogen bonds, Table S3. Selected hydrogen bonded dimers and calculated energies.

Author Contributions: Conceptualization, F.D. and D.D.; methodology, F.D., S.S., M.M.P. and I.C.M. (quantum computation); investigation, M.R.C., M.M.P. and I.C.M.; writing-original draft preparation, F.D., S.S., D.D. and M.M.P.; writing-review and editing, M.R.C.; supervision, F.D. All authors have read and agreed to the published version of the manuscript.

Funding: This research received no external funding.

Acknowledgments: MRC thanks the University of Cape Town for research support.

Conflicts of Interest: The authors declare no conflict of interest.

\section{References}

1. Desiraju, G.R.; Ho, P.S.; Kloo, L.; Legon, A.C.; Marquardt, R.; Metrangolo, P.; Politzer, P.; Resnati, G.; Rissanen, K. Definition of the halogen bond (IUPAC Recommendations 2013). Pure Appl. Chem. 2013, 85, 1711-1713. [CrossRef]

2. Cavallo, G.; Metrangolo, P.; Milani, R.; Pilati, T.; Priimagi, A.; Resnati, G.; Terraneo, G. The Halogen Bond. Chem. Rev. 2016, 116, 2478-2601. [CrossRef] [PubMed]

3. Berger, G.; Frangville, P.; Meyer, F. Halogen bonding for molecular recognition: New developments in materials and biological sciences. Chem. Commun. 2020, 56, 4970-4981. [CrossRef] [PubMed]

4. Priimagi, A.; Cavallo, G.; Metrangolo, P.; Resnati, G. The halogen bond in the design of functional supramolecular materials: Recent advances. Acc. Chem. Res. 2013, 46, 2686-2695. [CrossRef]

5. Saccone, M.; Catalano, L. Halogen Bonding beyond Crystals in Materials Science. Phys. Chem. B 2019, 123, 9281-9290. [CrossRef]

6. Berger, G.; Soubhyea, J.; Meyer, F. Halogen bonding in polymer science: From crystal engineering to functional supramolecular polymers and materials. Polym. Chem. 2015, 6, 3559-3580. [CrossRef]

7. Ding, X.; Tuikka, M.; Haukka, M. Halogen Bonding in Crystal Engineering. In Recent Advances in Crystallography; Benedict, J.B., Ed.; IntechOpen: London, UK, 2012.

8. Mukherejee, A.; Tothadi, S.; Desiraju, G.R. Halogen Bonds in Crystal Engineering: Like Hydrogen Bonds yet Different. Acc. Chem. Res. 2014, 47, 2514-2524. [CrossRef]

9. Metrangolo, P.; Resnati, G. (Eds.) Halogen Bonding I: Impact on Materials Chemistry and Life Sciences; Springer: Cham, Switzerland, 2015.

10. Metrangolo, P.; Resnati, G.; Pilati, T.; Biella, S. Halogen Bonding in Crystal Engineering. Structure and Bonding; Springer: Belin/Heidelberg, Germany, 2007.

11. Bulfield, D.; Engelage, E.; Mancheski, L.; Stoesser, J.; Huber, S.M. Crystal Engineering with Multipoint Halogen Bonding: Double Two-Point Donors and Acceptors at Work. Eur. J. Chem. 2020, 26, 1567-1575. [CrossRef]

12. Sathisaran, I.; Dalvi, S. Engineering Cocrystals of Poorly Water-Soluble Drugs to Enhance Dissolution in Aqueous Medium. Pharmaceutics 2018, 10, 108. [CrossRef]

13. Bulfield, D.; Huber, S.M. Halogen Bonding in Organic Synthesis and Organocatalysis. Eur. J. Chem. 2016, 22, 14434-14450. [CrossRef]

14. Sutar, R.L.; Huber, S.M. Catalysis of Organic Reactions through Halogen Bonding. ACS Catal. 2019, 9, 9622-9639. [CrossRef]

15. Liu, X.; Toy, P.H. Halogen Bond-Catalyzed Povarov Reactions. Adv. Synth. Catal. 2020, 362, 3437-3441. [CrossRef]

16. Tepper, R.; Schubert, U.S. Halogen Bonding in Solution: Anion Recognition, Templated Self-Assembly, and Organocatalysis. Angew. Chem. Int. Ed. 2020, 57, 6004-6016. [CrossRef] [PubMed]

17. Kobayashi, Y.; Takemoto, Y. Reactions Catalyzed by 2-Halogenated Azolium Salts: From Halogen-Bond Donors to Brønsted-Acidic Salts. Synlett 2020, 31, 772-783. [CrossRef] 
18. Yang, H.; Wong, M.W. Application of Halogen Bonding to Organocatalysis: A Theoretical Perspective. Molecules 2020, 25, 1045. [CrossRef] [PubMed]

19. Auffinger, P.; Hays, F.A.; Westhof, E.; Ho, P.S. Halogen bonds in biological molecules. Proc. Natl. Acad. Sci. USA 2004, 101, 16789-16794. [CrossRef] [PubMed]

20. Lu, Y.; Wang, Y.; Zhu, W. Nonbonding interactions of organic halogens in biological systems: Implications for drug discovery and biomolecular design. Phys. Chem. Chem. Phys. 2010, 12, 4543-4551. [CrossRef]

21. Wilcken, R.; Zimmermann, M.O.; Lange, A.; Joerger, A.C.; Boeckler, F.M. Principles and Applications of Halogen Bonding in Medicinal Chemistry and Chemical Biology. J. Med. Chem. 2013, 56, 1363-1388. [CrossRef]

22. Scholfield, M.R.; Zanden, C.M.V.; Carter, M.; Ho, P.S. Halogen bonding (X-bonding): A biological perspective. Protein Sci. 2013, 22, 139-152. [CrossRef]

23. Ho, P.S. Halogen bonding in medicinal chemistry: From observation to prediction. Future Med. Chem. 2017, 9, 637-640. [CrossRef]

24. Bayse, C.A. Halogen bonding from the bonding perspective with considerations for mechanisms of thyroid hormone activation and inhibition. N. J. Chem. 2018, 42, 10623-10632. [CrossRef] [PubMed]

25. Heidrich, J.; Sperl, L.E.; Boeckler, F.M. Embracing the Diversity of Halogen Bonding Motifs in Fragment-Based Drug Discovery-Construction of a Diversity-Optimized Halogen-Enriched Fragment Library. Front. Chem. 2019, 7, 9. [CrossRef] [PubMed]

26. Nayak, S.K.; Terraneo, G.; Piacevoli, Q.; Bertolotti, F.; Scilabra, P.; Brown, J.T.; Rosokha, S.V.; Resnati, G. Molecular Bases for Anesthetic Agents: Halothane as a Halogen- and Hydrogen-Bond Donor. Angew. Chem. Int. Ed. 2019, 58, 12456-12459. [CrossRef] [PubMed]

27. Kryukova, M.A.; Sapegin, A.V.; Novikov, A.S.; Krasavin, M.; Ivanov, D.M. New Crystal Forms for Biologically Active Compounds. Part 2: Anastrozole as N-Substituted 1,2,4-Triazole in Halogen Bonding and Lp- $\pi$ Interactions with 1,4-Diiodotetrafluorobenzene. Crystals 2020, 10, 371. [CrossRef]

28. Erdeley, M. Halogen bonding in solution. Chem. Soc. Rev. 2012, 41, 3547-3557. [CrossRef] [PubMed]

29. Glasser, R.; Chen, N.; Wu, H.; Knotts, N.; Kaupp, M. ${ }^{13}$ C NMR Study of Halogen Bonding of Haloarenes: Measurements of Solvent Effects and Theoretical Analysis. J. Am. Chem. Soc. 2004, 126, 4412-4419. [CrossRef] [PubMed]

30. Jentzsch, A.V. Applications of halogen bonding in solution. Pure Appl. Chem. 2015, 87, 15-41.

31. Von der Heiden, D.; Vanderkooy, A.; Erdélyi, M. Halogen bonding in solution: NMR spectroscopic approaches. Coord. Chem. Rev. 2020, 407, 213147. [CrossRef]

32. Voelkel, M.H.H.; Wonner, P.; Huber, S.M. Preorganization: A Powerful Tool in Intermolecular Halogen Bonding in Solution. ChemistryOpen 2020, 9, 214-224. [CrossRef]

33. Clark, T.; Henneman, M.; Murray, J.S.; Politzer, P. Halogen bonding: The $\sigma$-hole. J. Mol. Model. 2007, 13, 291-296. [CrossRef]

34. Kolár, M.H.; Hobza, P. Computer modeling of halogen bonds and other $\sigma$-hole interactions. Chem. Rev. 2016, 116, 5155-5187. [CrossRef] [PubMed]

35. Wang, H.; Wang, W.; Jin, W.J. $\sigma$-Hole Bond vs $\pi$-Hole Bond: A Comparison Based on Halogen Bond. Chem. Rev. 2016, 116, 5072-5104. [CrossRef] [PubMed]

36. Clark, T. Halogen bonds and $\sigma$-holes. Faraday Discuss. 2017, 203, 9-27. [CrossRef]

37. Politzer, P.; Murray, J.S.; Clark, T.; Resnati, G. The sigma-hole revisited. Phys. Chem. Chem. Phys. 2017, 19, 32166-32178. [CrossRef] [PubMed]

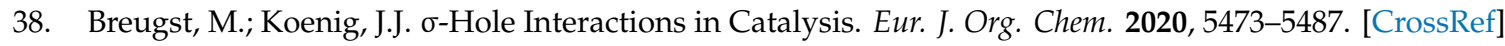

39. Lim, J.Y.C.; Beer, P.D. Sigma-Hole Interactions in Anion Recognition. Chem 2018, 4, 731-783. [CrossRef]

40. Murray, J.S.; Politzer, P. Interaction and Polarization Energy Relationships in $\sigma$-Hole and $\pi$-Hole Bonding. Crystals 2020, 10, 76. [CrossRef]

41. Pancholi, J.; Beer, P.D. Halogen bonding motifs for anion recognition. Coord. Chem. Rev. 2020, 416, 213281. [CrossRef]

42. Metrangolo, P.; Resnati, G. Type II halogen-Halogen contacts are halogen bonds. IUCrJ 2014, 1, 5-7. [CrossRef]

43. Ibrahim, M.A.A.; Moussa, N.A.M. Unconventional Type III Halogen $\cdots$ Halogen Interactions: A Quantum Mechanical Elucidation of $\sigma$-Hole $\cdots \sigma$-Hole and Di- $\sigma$-Hole Interactions. ACS Omega 2020, 5, 21824-21835. [CrossRef] 
44. Draghici, C.; Caira, M.R.; Dumitrescu, D.E.; Dumitrascu, F. Halogen Bonds of 4-Iodosydnones in Solution Deduced from ${ }^{13}$ C-NMR Spectra. Rev. Chim. 2018, 69, 843-846. [CrossRef]

45. Popa, M.M.; Shova, S.; Hrubaru, M.; Barbu, L.; Draghici, C.; Dumitrascu, F.; Dumitrescu, D.E. Introducing chirality in halogenated 3-arylsydnones and corresponding 1-arylpyrazoles obtained by 1,3-dipolar cycloaddition. RSC Adv. 2020, 10, 15656-15664. [CrossRef]

46. Popa, M.M.; Man, I.C.; Draghici, C.; Shova, S.; Caira, M.R.; Dumitrascu, F.; Dumitrescu, D. Halogen bonding in 5-iodo-1-arylpyrazoles investigated in the solid state and predicted by solution ${ }^{13} \mathrm{C}-\mathrm{NMR}$ spectroscopy. CrystEngComm 2019, 21, 7085-7093. [CrossRef]

47. Dumitrascu, F.; Draghici, C.; Dumitrescu, D.; Tarko, L.; Raileanu, D. Direct iodination of sydnones and their cycloadditions to form 5-iodopyrazoles. Liebigs Ann. Recl. 1997, 1997, 2613-2616. [CrossRef]

48. Dumitrascu, F.; Mitan, I.C.; Dumitrescu, D.; Drăghici, C.; Caproiu, M.T. Steric effects on the sydnones reactivity. New sydnones and pyrazoles. Arkivoc 2002, 2, 80-86. [CrossRef]

49. Dumitrascu, F.; Draghici, C.; Crangus, C.; Caproiu, M.T.; Mitan, C.I.; Dumitrescu, D.; Raileanu, D. Atropisomerism of new sterically hindered 1-arylpyrazoles. Rev. Roum. Chim. 2002, 47, 315-318. [CrossRef]

50. Dumitrascu, F.; Draghici, C.; Caproiu, M.T.; Crangus, C.; Mitan, C.I.; Barbu, L. Steric effects in the direct iodination and 1,3 dipolar cycloaddition of sydnones. Rev. Chim. (Bucharest) 2001, 52, 183-187.

51. CrysAlisPro Software System, Version 1.171.38.46; Oxford Diffraction Ltd., Rigaku Corporation: Oxford, UK, 2015.

52. Dolomanov, O.V.; Bourhis, L.J.; Gildea, R.J.; Howard, J.A.K.; Puschmann, H.J. OLEX2: A complete structure solution, refinement and analysis program. Appl. Cryst. 2009, 42, 339-341. [CrossRef]

53. Sheldrick, G. SHELXT-Integrated space-group and crystal-structure determination. Acta Cryst. A 2015, 71, 3-8. [CrossRef]

54. Sheldrick, G. Crystal structure refinement with SHELXL. Acta Cryst. C 2015, 71, 3-8. [CrossRef]

55. Wolff, S.K.; Grimwood, D.J.; McKinnon, J.J.; Turner, M.J.; Jayatilaka, D.; Spackman, M.A. (Eds.) CrystalExplorer, Version 3.1; University of Western Australia: Crawley, Australia, 2012.

56. Spackman, M.A.; Jayatilaka, D. Hirshfeld surface analysis. CrystEngComm 2009, 11, 19-32. [CrossRef]

57. Chevallier, F.; Halauko, Y.S.; Pecceu, C.; Nassar, I.; Dam, T.U.; Roisnel, T.; Matulis, V.E.; Ivashkevich, O.A.; Mongin, F. $\mathrm{N}$-aryl pyrazoles: DFT calculations of $\mathrm{CH}$ acidity and deprotonative metallation using a combination of lithium and zinc amides. Org. Biomol. Chem. 2011, 9, 4671-4684. [CrossRef] [PubMed]

58. Bondi, A. van der Waals Volumes and Radii. J. Phys. Chem. 1964, 68, 441-451. [CrossRef]

59. Frisch, M.J.; Trucks, G.W.; Schlegel, H.B.; Scuseria, G.E.; Robb, M.; Cheeseman, J.; Scalmani, G.; Barone, V.; Mennucci, B.; Petersson, G.; et al. Gaussian 09, Revision C.01; Gaussian, Inc.: Wallingford, CT, USA, 2009.

60. Becke, A.D. Density-functional thermochemistry. III. The role of exact exchange. J. Chem. Phys. 1993, 98, 5648-5652. [CrossRef]

61. Lee, C.; Yang, W.; Parr, R.G. Development of the Colle-Salvetti correlation-energy formula into a functional of the electron density. Phys. Rev. B 1988, 37, 785-789. [CrossRef] [PubMed]

62. Grimme, S.; Antony, J.; Ehrlich, S.; Krieg, H. A consistent and accurate ab initio parametrization of density functional dispersion correction (DFT-D) for the 94 elements H-Pu. J. Chem. Phys. 2010, 132, 154104. [CrossRef]

63. Godbout, N.; Salahub, D.R.; Andzelm, J.; Wimmer, E. Optimization of Gaussian-type basis sets for local spin density functional calculations. Part I. Boron through neon, optimization technique and validation. Can. J. Chem. 1992, 70, 560-571. [CrossRef]

64. Weigend, F.; Ahlrichs, R. Balanced basis sets of split valence, triple zeta valence and quadruple zeta valence quality for H to Rn: Design and assessment of accuracy. Phys. Chem. Chem. Phys. 2005, 7, 3297-3305. [CrossRef]

65. Nwachukwu, C.I.; Bowling, N.P.; Bosch, E. C-I $\cdots \mathrm{N}$ and C-I $\cdots \pi$ halogen bonding in the structures of 1-benzyliodoimidazole derivatives. Acta Crystallogr. Sect. C Struct. Chem. 2017, 73, 2-8. [CrossRef]

Publisher's Note: MDPI stays neutral with regard to jurisdictional claims in published maps and institutional affiliations. 